Document downloaded from:

http://hdl.handle.net/10251/102745

This paper must be cited as:

Dhakshinamoorthy, A.; Asiri, AM.; García Gómez, H. (2017). Metal Organic Frameworks as Versatile Hosts of Au Nanoparticles in Heterogeneous Catalysis. ACS Catalysis. 7(4):28962919. doi:10.1021/acscatal.6b03386

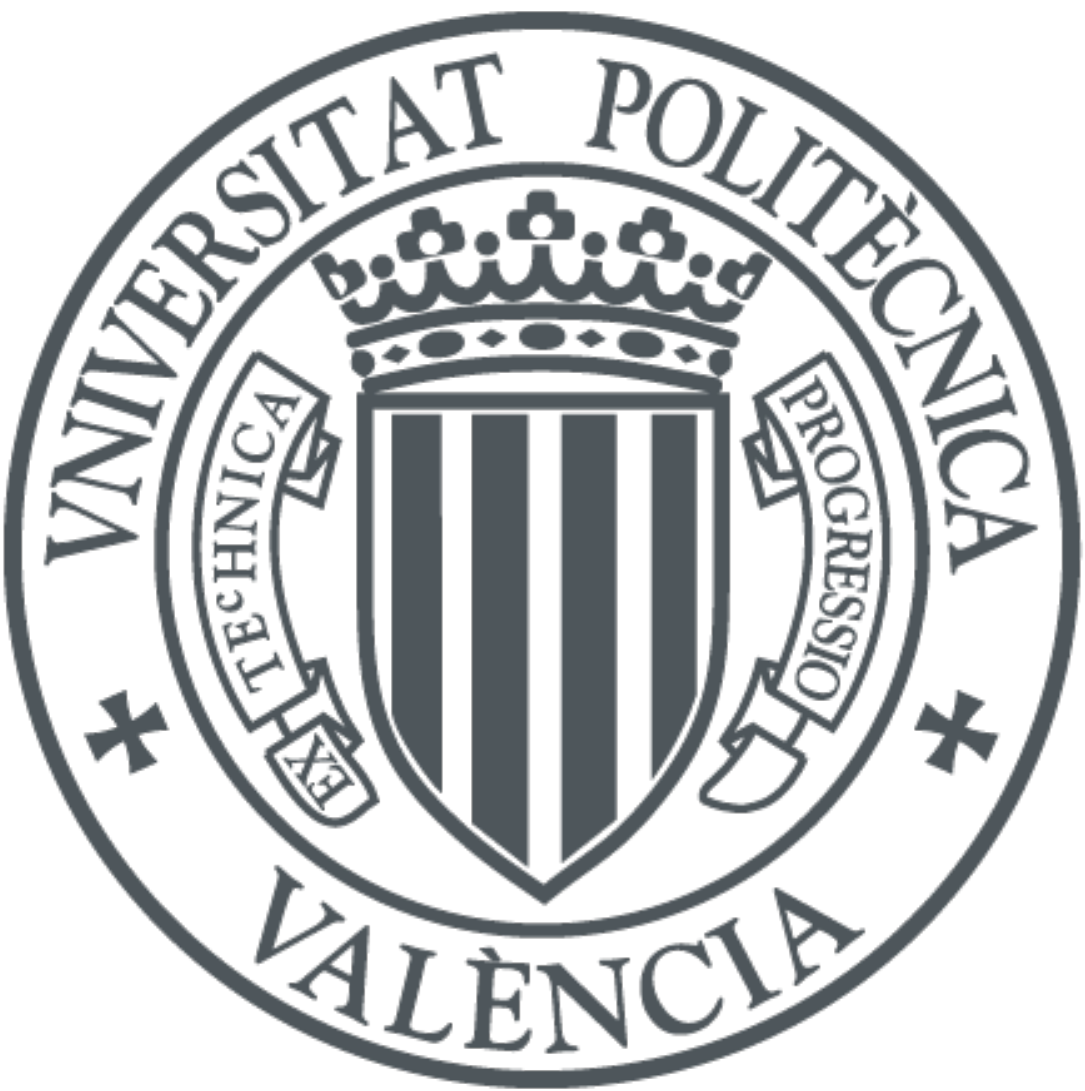

The final publication is available at

http://dx.doi.org/10.1021/acscatal.6b03386

Copyright American Chemical Society

Additional Information 


\title{
Metal Organic Frameworks as Versatile Hosts of Au Nanoparticles in Heterogeneous Catalysis
}

\author{
Amarajothi Dhakshinamoorthy, ${ }^{\mathrm{a}, \mathrm{b} *}$ Abdullah M. Asiri, ${ }^{\mathrm{c}}$ Hermenegildo Garcia ${ }^{\mathrm{b}, c *}$
}

aSchool of Chemistry, Madurai Kamaraj University, Tamil Nadu, India 625021 . E-mail: admguru@gmail.com

bInstituto Universitario de Tecnología Química CSIV-UPV, Universitat Politècnica de València, Av. De los Naranjos s/n, 46022, Valencia, Spain. E-mail: hgarcia@qim.upv.es

${ }^{c}$ Centre of Excellence for Advanced Materials Research, King Abdulaziz University, Jeddah, Saudi Arabia.

\section{Abstract}

The present review describes the state of the art of the use of metal organic framework (MOF) encapsulated Au nanoparticles (NPs) as heterogeneous catalysts. The purpose is to show that catalysts with very good performance, frequently among the most active Au catalysts reported so far, can be obtained by incorporation of Au NPs inside MOFs. The available data indicate that the high catalytic activity of MOF encapsulated Au NPs derives from i) small particle size, ii) high dispersion and homogeneous distribution inside MOFs crystals, iii) stabilization of particle size by confinement of Au NPs inside MOFs cages, and iv) the synergy that can arise by the combination of the activity of Au NPs and MOFs. After some introductory sections presenting general issues commenting about the relevance of $\mathrm{Au}$ catalysis, how to determine the internal vs. external location of Au NPs and evidences in support for catalyst stability, this mini review covers reactions using Au@MOFs as catalysts for oxidations, reductions, tandem process and photocatalysis with the emphasis in providing a comparison with the performance of other alternative Au containing catalysts. In the final section, we summarize in our view the current achievements and which are the next targets in this area. 
Keywords: Heterogeneous Catalysis; Metal Organic Frameworks; Au catalysis; Aerobic oxidations; Reduction reactions; Tandem reactions; Photocatalysis 


\section{Introduction}

Metal organic frameworks (MOFs) are increasingly used in heterogeneous catalysis ${ }^{1-7}$ mainly due to their intrinsic activity derived from the presence of metal ions having coordinatively exchangeable positions or to the substituents at the organic linker. But MOFs can also act as hosts of catalytically active guests. ${ }^{8,9}$ MOFs are porous crystalline materials in where the lattice contains metal ions or metal clusters held by rigid, normally aromatic, bi- or multipodal organic linkers. ${ }^{10-15}$ A large diversity of MOFs of virtually any transition metal as well as alkaline earth and rare earth metals has been reported. ${ }^{5}$ One of the important features that make MOFs so appropriate in heterogeneous catalysis is their high porosity and large surface area. ${ }^{16,17}$ In fact, MOFs are among the solids with the lowest framework density, meaning that the mass in a certain volume in the case of MOFs is frequently the minimum among the materials reported so far, thus, exhibiting frameworks with a high proportion of empty space. The specific pore volume and surface area of some robust MOFs is much larger than zeolites and even mesoporous silicas, reaching values about $1 \mathrm{~cm}^{3} \times \mathrm{gg}^{-1}$ and over 4000 $\mathrm{m}^{2} \times \mathrm{g}^{-1}$, respectively,(Volkringer, C.; Popov, D.; Loiseau, T.; Férey, G.; Burghammer, M.; Riekel, C.; Haouas, M.; Taulelle, F., Synthesis, Single-Crystal X-Ray Microdiffraction, and Nmr Characterizations of the Giant Pore Metal-Organic Framework Aluminum Trimesate Mil-100. Chemistry of Materials 2009, 21, 5695-5697.). This high pore volume makes MOFs particularly suited to incorporate guests that can exhibit catalytic activity, ${ }^{8}$ the role of MOFs being as insoluble supports allowing easy recovery of the occluded guests and also providing stabilization of the guest under reaction conditions due to its confinement, geometric restrictions and by establishing metal-support interactions, particularly dipolar Coulombic interactions with the metal nodes, $\pi$ interactions with organic aromatic linkers and even specific forces with substituents on the organic linker. 
Compared to zeolites, MOFs have special features including large flexibility in the composition containing a large percentage of transition metal, the possibility to anticipate the structure based on the knowledge of the inorganic node coordination mode and the directionality of the organic linker and the possibility to prepare isomorphic structures by changing ligand substitution.(Cheetham, A. K.; Ferey, G.; Loiseau, T., Open-Framework Inorganic Materials. Angewandte Chemie-International Edition 1999, 38, 3268-3292; Eddaoudi, M.; Moler, D. B.; Li, H. L.; Chen, B. L.; Reineke, T. M.; O'Keeffe, M.; Yaghi, O. M., Modular Chemistry: Secondary Building Units as a Basis for the Design of Highly Porous and Robust Metal-Organic Carboxylate Frameworks. Accounts of Chemical Research 2001, 34, 319-330; Ferey, G., Hybrid Porous Solids: Past, Present, Future. Chemical Society Reviews 2008, 37, 191-214; Yaghi, O. M.; O'Keeffe, M.; Ockwig, N. W.; Chae, H. K.; Eddaoudi, M.; Kim, J., Reticular Synthesis and the Design of New Materials. Nature 2003, 423, 705-714.) The versatility of MOF synthesis also allows the preparation of mixed-metal and mixed-ligand MOFs, either directly by synthesis or by post-synthetic modifications, in a large range of compositions.

Among the preferred guests that have been encapsulated inside MOFs for their use in catalysis, metal nanoparticles (MNPs) have been the most widely studied..$^{18-21}$ In the present short review, we will focus on the case of Au NPs encapsulated inside MOFs trying to illustrate the advantages that for a series of reactions derive from encapsulation of Au NPs inside MOFs as compared to other alternative catalysts. Although we will limit ourselves to the case of $\mathrm{Au}$, it is clear that similar examples of high performing catalysts prepared by incorporation of other MNPs on MOFs can also be found in the literature, particularly for noble metals such as $\mathrm{Pd}$, Pt or semi noble metals such as $\mathrm{Ru} .{ }^{18}$ Accordingly, the aim of the present review is to summarize the current state of the art of MOFs as hosts of Au NPs and those reactions in 
which the strategy based on encapsulation of Au NPs inside the pores of MOFs has proven to be successful to stabilize Au NPs. ${ }^{22}$

\section{Why focusing on Au?}

One of the main reasons for inclusion of MNPs inside porous hosts is to achieve stabilization of small MNPs under the reaction conditions, avoiding their growth and aggregation. This effect is achieved by establishing strong metal-support interactions and by geometrical constraints imposed by the size of the host pores. Aromatic polymers can establish strong $\pi$ interactions with Au NPs, surrounding and stabilizing them. Some Au NPs embedded in polystyrene copolymers have been reported among the most active Au catalysts for the aerobic oxidation of alcohols.(Miyamura, H.; Matsubara, R.; Miyazaki, Y.; Kobayashi, S., Aerobic Oxidation of Alcohols at Room Temperature and Atmospheric Conditions Catalyzed by Reusable Gold Nanoclusters Stabilized by the Benzene Rings of Polystyrene Derivatives. Angewandte Chemie-International Edition 2007, 46, 4151-4154; Perez, Y.; Aprile, C.; Corma, A.; Garcia, H., Comparison of the Catalytic Activity of Gold Nanoparticles Supported in Ceria and Incarcerated in Styrene Copolymer. Catalysis Letters 2010, 134, 204-209.) Also the external surface of inorganic metal oxides can adsorb Au NPs by van der Waals forces, dipole interactions and Coulombic attraction, large surface area metal oxides such as $\mathrm{TiO}_{2},{ }^{23,24}$ $\mathrm{CeO}_{2},{ }^{25-27}$ silica ${ }^{28}$ and alumina ${ }^{29,30}$ being among the preferred supports for Au NPs in catalysis. In this way, non-porous materials can stabilize small sized Au NPs. Similar interactions can be established with the internal surfaces of porous hosts, plus the additional effect of geometrical restrictions imposed by confinement inside the pores of the host, whose structure limits Au NP growth.

Au catalysis is one of the best cases to illustrate the potential of MOFs as hosts of MNPs, since from the pioneer work of Haruta, ${ }^{31}$ it has been well established that the catalytic activity of 
$\mathrm{Au}$ is only observed when the particle size of $\mathrm{Au}$ is below $10 \mathrm{~nm}$, there being a clear relationship between catalytic activity and average particle size for this metal. ${ }^{32-35}$ This means that the catalytic properties of a particular MNP can be dramatically influenced by the particle size. The proven fact is that Au NPs with diameters of about $5 \mathrm{~nm}$ or less have unique activity to promote some chemical reactions that is not observed for larger Au NPs. ${ }^{36}$ Several explanations for the remarkable catalytic activity of particles of such small size have been proposed, including quantum size effects, ${ }^{37}$ charge transfer to and from the support, ${ }^{38}$ oxygen spill-over to and from the support, ${ }^{39}$ and the stabilization of positive Au oxidation states. ${ }^{40}$ In some cases, it is likely that several of the above mentioned factors contribute simultaneously to the observed activity. In any case, all the above properties of NPs derive from the large percentage of atoms located at the external surface and having unsaturated coordination positions available to participate in catalysis. Considering a simple full-shell model with a 12 coordination for Au atoms in the Au lattice, it can be calculated that the percentage of the total Au atoms that are located at the surface in NPs of 1 and $2 \mathrm{~nm}$ is 52 and $35 \%$, respectively, but this percentage lowers exponentially with the diameter and becomes a few percents for NPs of $10 \mathrm{~nm}$.(Corma, A.; Garcia, H., Supported Gold Nanoparticles as Oxidation Catalysts. In Nanoparticles and Catalysis, Astruc, D., Ed. Wiley: New York, 2008; pp 389-426.) Other noble metals such as $\mathrm{Pd}$ or Pt that exhibit much higher intrinsic catalytic activity than $\mathrm{Au}$ are less influenced by the average NP size and activity can be still observed for NP of relatively large particle size. In contrast, the case of $\mathrm{Au}$ is particularly sensitive to the particle dimension in the nanometric range. For this reason, in the case of $\mathrm{Au}$, it has been so important to devise strategies to stabilize small NPs and this is the reason why Au has been selected in the present mini review to illustrate the potential of MOFs as hosts. 


\section{Internal vs. external location of Au NPs.}

One of the general issues when incorporating guests inside a porous solid is how to convincingly determine the distribution of the guests between the internal or external location of the host particles. Since MOFs are relatively new materials, this recurrent issue of the internal vs. the location was already addressed in other porous materials, such as zeolites and mesoporous silicas. Most of the available information on the guest location constitutes indirect evidences based on characterization and reactivity data. As a general remark it has to be admitted that most of these indirect data do not prove on solid ground the internal location and it is always advisable to combine the information of as many as possible of these techniques.

Thus, in the case of MNPs and particularly Au NPs that can be easily detected in electron microscopy, a prerequisite to claim internal location is the observation of a narrow particle size commensurate with the pore size. However, even if the Au NPs are small, they could be on the external surface and there are many examples of non-porous solids in which the Au NP size is of a few nanometers, in many cases below $5 \mathrm{~nm}$ and occasionally even of 2 $\mathrm{nm}$.(ref) This information by electron microscopy has to be combined with a decrease in the pore volume and surface area of the host, measured by isothermal gas adsorption. However, the decrease in surface area and pore volume can be due also to some external particles blocking the pores and impeding the access to some regions of the porous crystallites.

Other evidences that have been provided are based on changes in the catalytic activity compatible with the internal location.(Choi, M.; Wu, Z.; Iglesia, E., Mercaptosilane-Assisted Synthesis of Metal Clusters within Zeolites and Catalytic Consequences of Encapsulation. Journal of the American Chemical Society 2010, 132, 9129-9137; Otto, T.; Ramallo-Lopez, J. M.; Giovanetti, L. J.; Requejo, F. G.; Zones, S. I.; Iglesia, E., Synthesis of Stable Monodisperse 
Aupd, Aupt, and Pdpt Bimetallic Clusters Encapsulated within Lta-Zeolites. Journal of Catalysis 2016, 342, 125-137; Otto, T.; Zones, S. I.; Iglesia, E., Challenges and Strategies in the Encapsulation and Stabilization of Monodisperse Au Clusters within Zeolites. Journal of Catalysis 2016, 339, 195-208; Wu, Z.; Goel, S.; Choi, M.; Iglesia, E., Hydrothermal Synthesis of Lta-Encapsulated Metal Clusters and Consequences for Catalyst Stability, Reactivity, and Selectivity. Journal of Catalysis 2014, 311, 458-468.) For instance, common experiments involve the study of the influence of the bulkiness of substrates. Upon increasing molecular size, diffusion coefficients of substrates inside the pores of the host should decrease, up to one point in which no reaction should occur in comparison with other congeners whose dimensions are smaller. However, since the bulkiness of a given substrate also alters considerably its reactivity and organic chemistry has many examples of steric control of the functional group reactivity, conclusions should be based on comparison of the catalytic behaviour of zeolite encapsulated Au NPs with respect to Au NPs on the external surface of silica. However, even in this comparison other factors controlling activity can overlap with the location of the Au NPs, determining differences in reactivity, for instance, between ethylene and isobutene. The use of soluble poisons to quench external or leached metal species that could migrate from the solid to the liquid phase is another kinetic indirect proof that can be presented. Typical poisons for noble metals are sulfur species and even $\mathrm{Hg}$ particles. However, one can argue that these poisons can adsorbed on the external surface of the solid and can quench or influence even heterogeneous processes.

The overall conclusion of the current state of the art is that the internal location of $\mathrm{Au}$ NPs inside MOFs is not an easy issue that can be addressed just by providing the particle size distribution from transmission electron microscopy (TEM) and surely requires more attention 
and experimental support than those commonly provided in most of the references discussed in the present review. More efforts should be made to prove the internal location.

In one of the rare studies specifically dealing with the internal location of Au NPs inside UiO-66, recent advances in the area of electron microscopy to record tomographic images of MOF particles with nanometric shift in the vertical axis of the images was able to provide a 3D image of MOF particles, showing according to these 3D reconstruction images that Au NPs are mostly located inside MOFs crystallites (Moorthy it is ref. 71 Karen Leus and Abdessamad Grirrane). It should be, however, commented that even if the technique indicates that most Au NPs are inside the MOF, the size of some individual Au NPs is still larger than allowed. It could be that Au NPs extend through more than one cavity of the host or that Au NPs generate defects and imperfections in the relatively soft MOF crystallite by removing some linkers or metal nodes in MOF. The importance of defects on MOFs on its properties is being increasingly recognised in the field.( Fang, Z.; Bueken, B.; De Vos, D. E.; Fischer, R. A., DefectEngineered Metal-Organic Frameworks. Angewandte Chemie International Edition 2015, 54, 7234-7254.) Whatever the reason, tomography reconstruction of 3D MOF particles by combining several TEM images of the same particle focusing a few nanometers differently in the vertical axis is, probably, the best evidence provided that Au NPs are predominantly located inside MOFs.

\section{Incorporation of Au NPs}

Another important point to be considered when preparing Au@MOF samples is the experimental procedure to perform guest incorporation. Therefore, it can be recommended to follow reliable protocols to prepare small MNPs incorporated exclusively or predominantly inside the pores of MOFs, avoiding or minimizing the presence of these MNPs on the external 
surface. In this context, recently, a procedure denoted as "double solvents" method ${ }^{41}$ has been proposed to avoid MNP aggregation on the external surface of MOFs. The method is based on the use of a hydrophilic solvent (water) in a volume equal or less than the internal pore volume of the MOF and a hydrophobic solvent (hexane) in a large amount. The hydrophilic solvent contains the metal precursor and should be completely adsorbed by the hydrophilic internal pores of the MOF. The hydrophobic solvent plays the role to suspend the MOF crystals and facilitate the impregnation process. This double solvent method has been used, for instance to incorporate Pt NPs inside MIL-101(Cr) (MIL: Materials Institut Lavoisier). ${ }^{41}$ Since the inner surface area of MIL-101 is much larger than the outer surface area, the small amount of aqueous $\mathrm{H}_{2} \mathrm{PtCl}_{6}$ in a small solvent volume (equal or less than pore volume) can be completely adsorbed inside the hydrophilic pores by capillary forces, which greatly minimizes the deposition of $\mathrm{H}_{2} \mathrm{PtCl}_{6}$ on the outer surface. In contrast, in the conventional single-solvent impregnation process, a large amount of solvent containing the metal precursor is used, some of which will be deposited on the outer surfaces of MOF after drying, generating aggregated MNPs on the outer surfaces. This double solvent method was successfully employed for the preparation of MNPs presumably exclusively inside the pores, of MOFs in Pt@MIL-101(Cr), ${ }^{42}$ AuNi@MIL-101(Cr), ${ }^{43}$ Pd@MIL-100(Fe), ${ }^{44}$ Pd@NH $2-U i O-66{ }^{45}$ and the resulting MOFs used as catalysts for ammonia borane hydrolysis, $\mathrm{N}$-alkylation of amines with alcohols and visible-light-promoted Suzuki coupling reaction. It is, however, worth noting that the double solvent protocol has not yet been applied for the preparation of Au NPs incorporated in MOFs.

In spite of the claimed advantages of the recently developed double solvent method, the two most-frequently used approaches to prepare MNPs onto the porous of MOFs are adsorption of suitable precursors or inclusion of preformed Au NPs. ${ }^{19,46,47}$ The first and most 
widely used method is to initially adsorb a suitable metal precursor inside the cavity of MOFs which subsequently is reduced to generate MNPs. ${ }^{48-52}$ In this way, the growth of MNPs is controlled by the pore dimension of the respective MOFs. However, as commented earlier the issue is the place where the deposition of the particles takes place either on the outer/inner surface of MOF structure. The second and most recent approach is to presynthesise MNPs by capping with polymer and then, the MOF structure is allowed to construct around it with appropriate chemicals. ${ }^{53,54}$ Metal ions and organic linkers that should can interact with the embedded MNPs by coordination and $\pi-\pi$ forces and can start to nucleate around these MNPs. ${ }^{17}$ In this case, although incorporation of MNPs inside MOF pores has still been reported in some cases, most frequently MOF coats MNPs forming a shell around MNPs.(He, L.; Liu, Y.; Liu, J.; Xiong, Y.; Zheng, J.; Liu, Y.; Tang, Z., Coreshell NobleMetal@Metal-Organic-Framework Nanoparticles with Highly Selective Sensing Property. Angewandte Chemie-International Edition 2013, 52, 3741-3745; Hu, P.; Morabito, J. V.; Tsung, C.-K., Core-Shell Catalysts of Metal Nanoparticle Core and Metal-Organic Framework Shell. Acs Catalysis 2014, 4, 4409-4419; Ke, F.; Zhu, J.; Qiu, L.-G.; Jiang, X., Controlled Synthesis of Novel Au@Mil-100(Fe) Core-Shell Nanoparticles with Enhanced Catalytic Performance. Chemical Communications 2013, 49, 1267-1269; Kuo, C.-H.; Tang, Y.; Chou, L.-Y.; Sneed, B. T.; Brodsky, C. N.; Zhao, Z.; Tsung, C.-K., Yolk-Shell Nanocrystal@Zif-8 Nanostructures for GasPhase Heterogeneous Catalysis with Selectivity Control. Journal of the American Chemical Society 2012, 134, 14345-14348; Liu, Y.; Tang, Z., Multifunctional Nanoparticle@Mof CoreShell Nanostructures. Advanced Materials 2013, 25, 5819-5825.) Access to the MNP core has to occur through the MOF shell and this layer controls the traffic of substrate and the activity of the MNP core. Similar approach can be used to coat metal oxide NPs or nanorods with magnetic and (photo)catalytic activity by MOFs that serve as gates to access the metal 
oxide.(Chen, X.; Ding, N.; Zang, H.; Yeung, H.; Zhao, R.-S.; Cheng, C.; Liu, J.; Chan, T. W. D., Fe3o4@Mof Core-Shell Magnetic Microspheres for Magnetic Solid-Phase Extraction of Polychlorinated Biphenyls from Environmental Water Samples. Journal of Chromatography $A$ 2013, 1304, 241-245; Zhan, W.-w.; Kuang, Q.; Zhou, J.-z.; Kong, X.-j.; Xie, Z.-X.; Zheng, L.-S., Semiconductor@Metal-Organic Framework Core-Shell Heterostructures: A Case of Zno@Zif8 Nanorods with Selective Photoelectrochemical Response. Journal of the American Chemical Society 2013, 135, 1926-1933; Zhang, C.-F.; Qiu, L.-G.; Ke, F.; Zhu, Y.-J.; Yuan, Y.-P.; Xu, G.-S.; Jiang, X., A Novel Magnetic Recyclable Photocatalyst Based on a Core-Shell Metal-Organic Framework Fe304@Mil-100(Fe) for the Decolorization of Methylene Blue Dye. Journal of Materials Chemistry A 2013, 1, 14329-14334; Zhang, T.; Zhang, X.; Yan, X.; Kong, L.; Zhang, G.; Liu, H.; Qiu, J.; Yeung, K. L., Synthesis of Fe3o4@Zif-8 Magnetic Core-Shell Microspheres and Their Potential Application in a Capillary Microreactor. Chemical Engineering Journal 2013, $228,398-404$.) Typically, MOFs whose synthesis can be performed at room temperature or under mild conditions, like ZIF-8 or MOF-5, have been the preferred ones to achieve the overlayer of MPNs. However, although some examples of this core-shell Au NP-MOF will be commented in section 9, this growing field is mostly not covered in the present review that is focused on those materials in which Au NPs are incarcerated inside the pores of MOFs.

Besides the process of MNP incorporation, one of the major issues is to avoid MNP agglomeration upon increasing their loading amount on MOFs. In the case of Pd NPs, this issue has been addressed by functionalization of MOFs with alkyne groups. ${ }^{55}$ The single crystal structure of the Zn-MOF of the corresponding mixed ligand 3-(propynyloxy)isophthalic and 1,4-(dipyridinyl)benzene showed that the ethynyl moieties are pointing toward the pore. It is well known that some late transition metal ions can strongly interact with the ethynyl 
functionality through the formation of $\sigma$ and $\pi$ bonds. ${ }^{56,57}$ (Grirrane 2013, leyva-Perez 2013, Maity 2013) This allows to stabilize noble metal ions preferentially and thus can facilitate significantly high metal loading into MOFs, reducing leaching significantly. The ease in which MOFs can be designed and adapted for a specific application, like as hosts of high MNP loadings, reaching $27 \mathrm{wt} . \%$. This strategy has also been applied to prepare high loadings of Au NPs inside these functionalized Zn-MOFs, reaching up to 50 wt.\% as it will be described in section 9.(Gole 2015)

\section{Stability of Au@MOF catalysts.}

Besides their easy separation from the reaction mixture, one of the main reasons to use heterogeneous catalysts is the possibility to reuse the same sample in consecutive runs. This requires catalyst stability under the reaction conditions and catalytic studies should include kinetic data and structural information supporting this stability, meaning that the sample does not decrease in activity upon reuse and determining which are the major deactivation pathways.

In this regard, it is worth commenting that most of the studies claiming stability of Au@MOF lack convincing evidence to support this claim of stability on firm ground, particularly kinetic evidence. Even though the series of experiments provided in support of the claim of Au@MOF stability are frequently similar in most of the works, they do not provide kinetic information of reaction upon reuse of the same sample and, on top of that, the number of reuses is generally limited to only a few. Catalyst stability is convincingly proved by presenting the temporal evolution of substrates and products and showing that these profiles are coincident in many cycles.(ref of Topic Catalysis of Chris Jones) By giving only 
conversions and selectivities or product yields at final time, changes in the initial reaction rates that would indicate catalyst deactivation cannot be observed.

Catalysts stability also requires that the structure of the catalyst and Au content and size distribution do not change after many reuses. In the case of Au@MOF this structural stability of the host can be checked by XRD and electron microscopy, among other techniques. XRD should show that the crystallinity of the MOF is preserved under the reaction conditions. Chemical analyses of solid and liquid should determine the absence of $\mathrm{Au}$ in the liquid phase and that Auy loading has been maintained. TEM images should reveal that the Au NP size distribution of the used sample is coincident with that of the fresh sample. In many examples, determination of the particle size distribution upon reuse has shown that MOFs provide sufficient stability to incorporated Au NPs minimizing their growth.

As it will be shown later, one of the key points in developing a successful MOFencapsulated Au catalyst is the selection of a structurally robust MOF. It is a general misconception that all MOFs are labile materials. However, by now there are sufficiently large numbers of examples of MOFs that can stand very harsh conditions without undergoing deterioration of their crystallinity. ${ }^{58,59}$ The examples of these robust MOFs include some MIL materials as well as UiO solids (UiO: University of Oslo). For instance, in the case of MIL-101, it is possible to submit the solid to treatment with strong, corrosive Brönsted acids such as nitric or chlorosulfonic acid to introduce functionality on the aromatic ligand without destroying or damaging the crystallinity. Nitration and sulfonation of deactivated aromatic compounds are among the organic reactions that require harsher conditions and crystal stability of MIL-101 is sufficiently high to allow performing these reactions at the linker without damaging the lattice. It is, however, clear that this structural robustness is not general for every MOF material and that there are many other MOFs whose structure can deteriorate 
under much milder conditions. ${ }^{60,61}$ For this reason, it is always necessary to select as host those MOFs that can stand the reaction conditions. In addition, these MOFs should also enjoy high porosity and, as it will be shown later, MIL-101(Cr, Fe), MIL-100, UiO-66 are among the hosts for which Au embedded catalysts exhibit the highest activity, frequently higher than on other supports.

\section{Au@MOF as catalysts.}

To illustrate the advantages of MOF-encapsulated Au catalysts some reaction types for which it is known that Au exhibits high activity have selected. Thus, the activity of Au/MOFs for aerobic oxidations of benzyl alcohols, benzylic hydrocarbons and cycloalkanes as well as selective $\mathrm{CO}$ oxidation will be presented (sections 7 and 8 ). Other reaction type that has been widely studied with Au catalysts is the reduction of nitro aromatics for which there is also abundant literature data (section 9). ${ }^{62}$ Besides oxidations and reductions, tandem reactions will be commented (section 10). Thus, besides the passive role of MOFs defining cavities to incorporate Au NPs where the reaction takes place, the special composition of MOFs can be adequate to play also an active role in the process, resulting in a synergy by combining the properties of Au NPs and MOFs. Thus, it will be shown that in some cases, both Au and MOFs have intrinsic activity to promote the reaction, as for instance in cyclohexane oxidation. In other cases, the activity of Au and MOFs are complimentary, each of them catalyzing different steps, and, therefore, tandem reactions in where two or more different processes are combined in one step can be realized with these host-guest materials. ${ }^{63,64}$ For instance, Au NPs can promote oxidations, while MOFs can introduce acidity or basicity. It is clear that the combination of Au catalysis and an active role of MOFs offer a clear promise to develop many more new examples in the future. The last type of process that will be discussed is photocatalytic $\mathrm{CO}_{2}$ reduction and photooxidation of benzyl alcohol (section 11) since the 
area of MOFs as photocatalysts is currently under intense investigation and there is again a clear synergy of combining MOFs as photoresponsive materials and Au NPs as cocatalysts. ${ }^{65}$ In these reactions, light is harvested by MOF host that undergoes photochemical excitation, while Au NPs as guests act as catalytic centres frequently accumulating electrons and converting substrates into products due to the energy captured by MOFs.

Table 1 lists the examples that will be presented in this review grouped according to the reaction type, making emphasis in the particle size and the evidence of catalyst stability.

Table 1. Summary of MOF encapsulated Au NPs as heterogeneous catalysts.

\begin{tabular}{|c|c|c|c|}
\hline Catalyst & $\begin{array}{l}\text { Particle size } \\
(\mathrm{nm})\end{array}$ & Stability evidence & Ref. \\
\hline \multicolumn{4}{|c|}{ Benzyl alcohol oxidation } \\
\hline $\mathrm{Au} / \mathrm{MIL}-53(\mathrm{Al})$ & $<1$ & - & 50 \\
\hline $\mathrm{Au} / \mathrm{ZIF}-8$ & 1 to 5 & - & 48 \\
\hline $\mathrm{Au} / \mathrm{TiO}_{2} @ \mathrm{MOF}-5$ & 1 to 3 & - & 66 \\
\hline $\mathrm{Au} / \mathrm{MIL}-101(\mathrm{Cr})$ & 2.3 & Leaching, TEM & 67 \\
\hline $\mathrm{Au} / \mathrm{PMA}-\mathrm{MIL}-101(\mathrm{Cr})$ & 2.5 & reuse & 68 \\
\hline $\mathrm{Au} / \mathrm{UiO}-66$ & 5 & Reuse, TEM & 69 \\
\hline $\mathrm{Au} / \mathrm{UiO}-66^{\mathrm{a}}$ & 7 & Leaching, TEM,XPS & 70 \\
\hline $\mathrm{Au@NH}$-UiO-66 & 2.8 & $\begin{array}{l}\text { Reuse, ICP, XRD, FT-IR, } \\
\text { SEM, TEM }\end{array}$ & 71 \\
\hline \multicolumn{4}{|c|}{ Benzylic/cycloalkane oxidation } \\
\hline $\mathrm{Au} / \mathrm{MIL}-53(\mathrm{Cr})$ and $\mathrm{Au} / \mathrm{MIL}-101(\mathrm{Cr})$ & $\begin{array}{l}4.8 \pm 2.9 \text { and } \\
1.8 \pm 0.6\end{array}$ & Reuse, TEM & 72 \\
\hline $\mathrm{Au}-\mathrm{Pd} / \mathrm{MIL}-101(\mathrm{Cr})$ & 2.40 & Reuse, XRD, AAS, TEM & 73 \\
\hline $\mathrm{Au}-\mathrm{Pd} / \mathrm{MIL}-101(\mathrm{Cr})$ & 3 & Reuse, leaching, TEM & 74 \\
\hline $\mathrm{Au}-\mathrm{Pd} / \mathrm{MIL}-101(\mathrm{Cr})$ & - & Reuse, XRD & 75 \\
\hline Au@UiO-66 & 2.8 & Reuse & 76 \\
\hline \multicolumn{4}{|c|}{ 4-nitrophenol reduction } \\
\hline Au@MIL-100(Fe) & $60^{b}$ & Reuse, XRD & 77 \\
\hline $\mathrm{Au@NH_{2 } - U i O - 6 6}$ & 2.8 & - & 71 \\
\hline $\mathrm{Au} / \mathrm{Cu}(\mathrm{II})-\mathrm{MOF}$ & 2 & XRD, HRTEM & 78 \\
\hline Au@MOF-1 & 2.87 & TEM & 79 \\
\hline $\mathrm{Au}-\mathrm{Fe}_{3} \mathrm{O}_{4} @ \mathrm{MIL}-100(\mathrm{Fe})$ & $3-5$ & Reuse & 80 \\
\hline rGO@Fe $\mathrm{F}_{3} @ \mathrm{MIL}-100 / \mathrm{Au}$ & 3 & Reuse, XPS, ICP & 81 \\
\hline Au@Ag/ZIF-8 & & Reuse, TEM & 82 \\
\hline
\end{tabular}




\begin{tabular}{|c|c|c|c|}
\hline $\mathrm{Au} @ \mathrm{Ag} / \mathrm{MIL}-101-\mathrm{SO}_{3} \mathrm{H}$ & $2-10$ & reuse & 83 \\
\hline AuAg@BIF-38 & 20 & Reuse, TEM & 84 \\
\hline \multicolumn{4}{|c|}{ Tandem reactions } \\
\hline Au@Cu(II)-MOF & 2 & Reuse, HRTEM & 78 \\
\hline $\mathrm{Au} @ \mathrm{NH}_{2}-\mathrm{MIL}-53(\mathrm{Al})$ & 2.5 & Reuse, ICP, XRD & 85 \\
\hline $\mathrm{Au} / \mathrm{MIL}-53(\mathrm{Al})$ & $1.6 \pm 1$ & - & 86 \\
\hline $\mathrm{Au@NH_{2 } - U i O - 6 6}$ & 2.8 & reuse & 71 \\
\hline Au@MOF-3 & 1.85 & - & 79 \\
\hline Au/IRMOF-3 & 3.3 & Reuse, TEM & 87 \\
\hline Au/CUP-1 & 2.1 & Reuse & 88 \\
\hline \multicolumn{4}{|c|}{ Photoredox reactions } \\
\hline $\mathrm{Au} / \mathrm{NH}_{2}-\mathrm{MIL}-125(\mathrm{Ti})$ & 2.5 & - & 89 \\
\hline Au@NH $\mathrm{NH}_{2}-\mathrm{UiO}-66$ & - & - & 90 \\
\hline
\end{tabular}

PMA: phenylene-mono(oxamate); CUP: China University of Petroleum; CUP-1: $\mathrm{Zn}_{2}(\mathrm{ABDC})(\mathrm{L}-$ lac)(HCOO) (ABDC: 2-amino-1,4-benzenedicarboxylic acid; L-lac: L-lactic acid; ${ }^{2}$ Under base-free

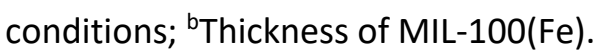

The overall purpose of this mini review is to provide an update of the current state of the art that has by now sufficient examples showing the advantages derived from encapsulation of Au NPs inside MOFs.

\section{Benzyl Alcohol Oxidation}

Benzyl alcohol is the favourite probe molecule to study the activity of Au catalysts for the aerobic oxidation of alcohols. ${ }^{91}$ Many Au catalysts exhibit activity for this process and it is difficult to rank them due to the various conditions used in these studies. Nevertheless, the key point in the process is to carry out this oxidation in the absence of base, at room or mild temperatures and with a reusable catalyst. It is generally accepted that the role of the base is to form alcoholate that will bound to the unsaturated Au atoms bearing positive charge density located at corners, edges and steps of the NP. Although mechanistic details are still not known, the key step in the oxidation is proposed to be the transfer of a $\alpha-\mathrm{H}$ from the alcoholate to $\mathrm{Au}$. Scheme \# illustrates elementary steps of the process. 


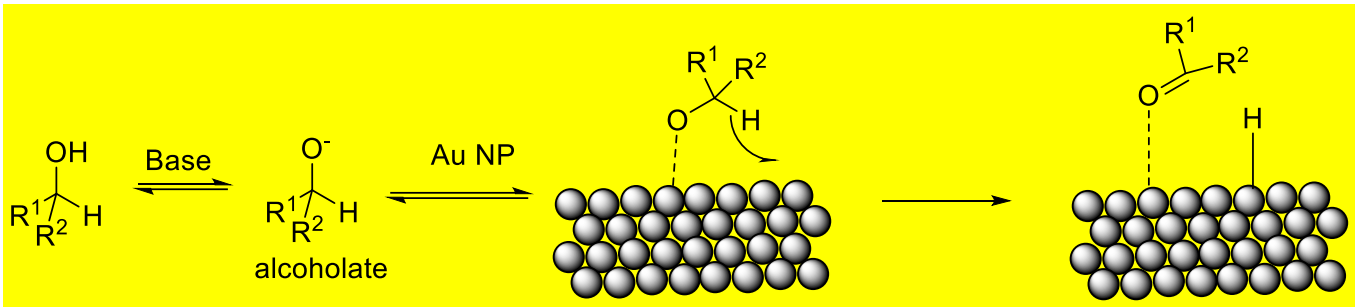

Scheme 1. General mechanism for alcohol oxidation by Au NPs.

Not surprisingly, this oxidation has also been frequently studied using MOFencapsulated Au NPs. In a seminal contribution, Au clusters were incorporated on several MOFs such as MOF-5, MIL-53(Al), and $\mathrm{Cu}_{3}(\mathrm{BTC})_{2}$ [BTC: 1,3,5-benzenetricarboxylate] using a volatile organogold complex, $\mathrm{Me}_{2} \mathrm{Au}(\mathrm{acac})$, (acac: acetylacetonate) as precursor. ${ }^{50}$ It was observed that the size of the incorporated Au NPs is strongly dependent on the nature of the MOF, its pore structure and pore size. This observation is in agreement with one of the expected roles of MOF that is the control of Au particle size by physical confinement of the NPs within the framework. Among the various MOFs used to incorporate Au, MIL-53(Al) showed the smallest particle size, below $1 \mathrm{~nm}$ that although does not prove the internal location of Au NPs is compatible with the dimensions of MIL-53(Al) pores.

The use of Au/MOF-5 as catalyst in the presence of base leads to $82 \%$ conversion of benzyl alcohol in $1 \mathrm{~h}$ using oxygen as oxidant resulting in the formation of $66 \%$ of methyl benzoate (Scheme 1) and $3 \%$ benzaldehyde, while in the absence of base, $69 \%$ conversion with $23 \%$ methyl benzoate and $31 \%$ benzaldehyde was achieved. Similarly, Au/MIL-53(AI) in the presence of base promoted the aerobic oxidation of benzyl alcohol with $98 \%$ conversion in $23 \mathrm{~h}$ and a selectivity of $2 \%$ of benzaldehyde and $77 \%$ of methyl benzoate. It should be, however, commented that the presence of base can cause the destruction of MOF crystal structure during the oxidation reaction and this will affect to the stability of the catalyst. In 
fact, as already commented, the selection of a robust MOF structure should be a prerequisite for these studies and the use of MOF-5 and $\mathrm{Cu}_{3}(\mathrm{BTC})_{2}$ with known poor stability is a limitation for their use as host of Au NPs. Au/MOF-5 (0.5 wt\% Au with a mean diameter of $4.8 \pm 2.2 \mathrm{~nm}$ ) prepared by solid grinding showed the highest catalytic activity for 1-phenylethanol oxidation in the presence of base among all the materials containing Au embedded on MOFs to give $79 \%$ yield of acetophenone. However, it is unlikely that Au NPs of such large size can fit inside the cavities of MOF-5 $(1.5 \mathrm{~nm})$ and that MOF-5 could be stable in the presence of base. Therefore, leaching tests during the oxidation reaction and stability of the catalyst under the reaction conditions would make a more realistic comparison of the catalytic performance of MOF-5 embedded Au with respect to other Au catalysts.

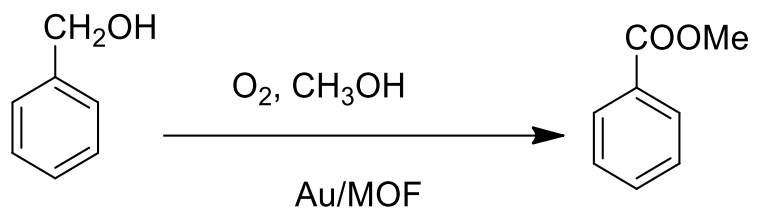

Scheme 1. Oxidation of benzyl alcohol catalyzed by Au NPs.

The loading and stabilization of small, naked metal NPs within the cavities of zeolite imidazolate frameworks (ZIFs), namely ZIF-8 (ZnIm2; Im: imidazolate) and ZIF-90 (Zn(ICA)2; ICA: imidazolate-2-carboxyaldehyde), as hosts was reported in order to gain control on the dispersion of embedded Au NPs. ${ }^{48}$ Figure 1 shows the structure of Au/ZIF-8 material. Homogeneous distribution of Au NPs throughout the ZIF matrix was observed with particle size ranging from 1 to $5 \mathrm{~nm}$. ZIF-8 and ZIF-90 showed no activity in the oxidation of benzyl alcohol in methanol, while Au/ZIF-8 and Au/ZIF-90 exhibited 81 and $13 \%$ conversion with the selectivity towards methyl benzoate of $98 \%$ and $50 \%$, respectively (Scheme 1 ). Also, a small amount of benzaldehyde was observed, but no formation of benzaldehyde dimethylacetal noticed. 


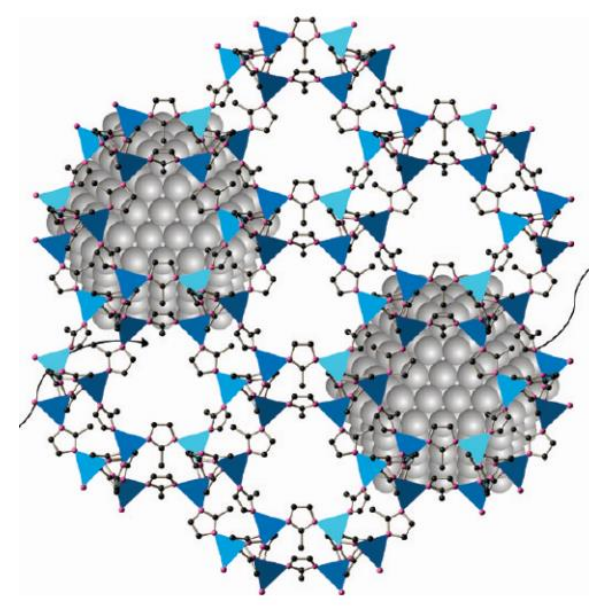

Figure 1. Structure of Au/ZIF-8. Taken with permission from ref. ${ }^{48}$

MOF-5 and the metal oxide containing materials $\mathrm{ZnO} / \mathrm{MOF}-5$ and $\mathrm{TiO}_{2} / \mathrm{MOF}-5$ were loaded with the precursor [ClAuCO] to yield intermediate materials namely [ClAuCO]/MOF-5, [ClAuCO]/ZnO@MOF-5 and [ClAuCO]/TiO $/$ MOF-5. ${ }^{66}$ These composites were decomposed by reduction with hydrogen at $100{ }^{\circ} \mathrm{C}$ to achieve Au/MOF-5, Au/ZnO@MOF-5 and $\mathrm{Au} / \mathrm{TiO}_{2} @ \mathrm{MOF}-5$. It is very interesting to note that metal and metal oxide particles are not separated in different regions of the crystalline MOF matrix, but are both present in every individual crystallite. Thus, Au NPs were distributed in a homogeneous fashion over the MOF matrix with a size of 1 and $3 \mathrm{~nm}$ that could be compatible with the internal location of some Au NPs. These MOF-5 based catalysts were used for the liquid phase oxidation of benzyl alcohol by molecular oxygen. None of these catalysts showed any activity in the absence of potassium carbonate, while in the presence of this base, Au/MOF- 5 showed $50 \%$ conversion of benzyl alcohol to $48 \%$ yield of methyl benzoate. The presence of metal oxide resulted in some increase of benzyl alcohol conversion. For example, Au/ZnO@MOF-5 and $\mathrm{Au} / \mathrm{TiO}_{2} @ \mathrm{MOF}-5$ exhibited $66 \%$ and $72 \%$ of methyl benzoate, respectively, in the presence of potassium carbonate. Although it appears that MOF-5 is not the best choice due to its poor 
lattice stability, this seminal work shows the possibility to prepare many of the metal oxidesupported Au catalysts widely studied in Au catalysis embedded with MOF matrices.

Au NPs incorporated on MIL-101(Cr) (see crystal lattice in Figure 2) by colloidal deposition with polyvinylpyrrolidine (PVP) as protecting agent exhibited the highest catalytic activity for aerobic oxidation of alcohols to aldehydes under base-free conditions. ${ }^{67}$ This higher activity may be due to the low mean diameter of Au NPs $(2.3 \mathrm{~nm})$ that can be achieved following the appropriate MIL-101(Cr) (two types of cavities of 3.0 and $3.8 \mathrm{~nm}$ diameter) loading method. However, how the preformed Au NPs stabilized by PVP diffuse inside the MOF particles is a matter that deserves further investigation. The activity of Au/MIL-101(Cr) is remarkably good, promoting the aerobic oxidation of benzylic alcohols to their corresponding aldehydes in almost complete conversion (>95\%) and selectivity (>99\%). Secondary aliphatic alcohols showed higher activity than primary counterparts. Further, alcohols having heteroatoms were also oxidized with high conversion and selectivity. No leaching of Au was observed under the experimental conditions and Au particle size before and after the oxidation reaction remains unaltered as evidenced by TEM analysis. The Au/MIL$101(\mathrm{Cr})$ material showed consistent yield (>99\%) up to sixth cycle for the oxidation of 4methoxybenzyl alcohol. This catalyst showed a very high TOF value of $29300 \mathrm{~h}^{-1}$ for the aerobic oxidation of 1-phenylethanol (Scheme 2). The high catalytic activity of this Aucontaining MOF arises from the robust structure of MIL-101(Cr) that can withstand water and organic solvents and the large pore size of MIL-101 (1.1 and $1.5 \mathrm{~nm}$ windows) facilitating mass transfer of reactant/product molecules inside the pores and the small Au NP size. In another precedent, Au/PMA-MIL-101 (PMA: phenylene-mono(oxamate)) with a Au content 1.5 wt\% having a particle size of $2.5 \mathrm{~nm}$ has been used as heterogeneous catalyst for the oxidation of benzyl alcohol under air atmosphere, observing $60 \%$ conversion with a TOF of $7 \mathrm{~min}^{-1}{ }^{68}$ At 
this moment, $\mathrm{Au} / \mathrm{MIL}-101(\mathrm{Cr})$ is the best performing MOFs encapsulated Au catalyst for aromatic alcohol oxidation, being remarkable its stability under base free conditions and the higher reactivity for secondary alcohols, something not frequently observed with other catalysts due to steric encumbrance of secondary alcohols. The next target would be to decrease the reaction temperature and to expand the scope to more challenging alcohols.

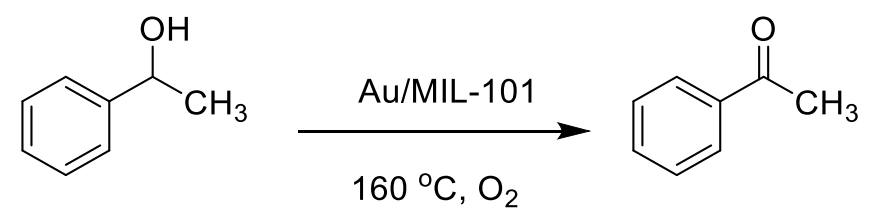

Scheme 2. Aerobic oxidation of 1-phenylethanol catalyzed by Au/MIL-101.

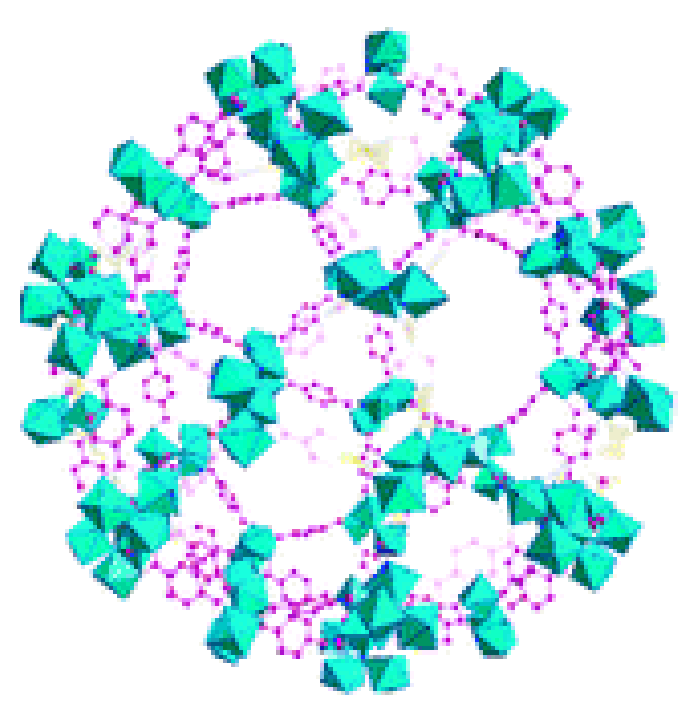

Figure 2. Crystal lattice of MIL-101(Cr). Taken with permission from ref. ${ }^{67}$

Besides MIL-101(Cr), UiO-66 is other type of robust MOF. Figure 3 shows the structures of UiO-66 and $\mathrm{NH}_{2}-\mathrm{UiO}-66$. Highly dispersed Au NPs have been encapsulated in UiO-66 and its activity was examined for the aerobic oxidation of benzyl alcohol under solvent-free conditions. ${ }^{69}$ Powder XRD and SEM images of Au/UiO-66 revealed that the crystallinity and morphology of UiO-66 (cavities of $3.6 \mathrm{~nm}$ ) is maintained during the loading of Au NPs. Au NPs particle of average size of $5 \mathrm{~nm}$ were formed within the pores of UiO-66 
without observing deposition of NPs on the external surface or aggregation. TGA analysis of Au/UiO-66 indicated that Au loading is $8 \%$. Under the optimized conditions, Au/UiO-66 promoted the oxidation of benzyl alcohol to benzaldehyde using $\mathrm{K}_{2} \mathrm{CO}_{3}$ as base in $53.7 \%$ yield after $10 \mathrm{~h}$ with a turnover number (TON) and turnover frequency (TOF) values of 9130 and $913 \mathrm{~h}^{-1}$, respectively. Furthermore, under identical conditions non-supported polyoxometallate and TEMPO gave 15.4 and $19.3 \%$ yields, which is significantly lower than Au/UiO-66 both in conversion and selectivity. The catalytic activity of Au/UiO-66 is comparable to that of the analogous catalysts reported in the literature for $\mathrm{Au} / \mathrm{Mn}-\mathrm{CeO}_{2}{ }^{92}$ and $\mathrm{Au} / \mathrm{CuO}^{93}$ that are among the most active supported Au catalysts with 42.8 and $57.4 \%$ yield of benzaldehyde, respectively. Furthermore, Au/UiO-66 was reused for at least eight times without any significant loss of activity. In fact, the reusability of Au/UiO-66 was much better than that of $\mathrm{Au} / \mathrm{TiO}_{2} \cdot{ }^{94}$ No obvious aggregation was observed during the recycling process as indicated by the TEM images. It is important to note that the stability of a catalyst must be supported by detailed kinetic studies by measuring initial reaction rates for each cycle, rather than reporting a yield at final reaction time. Later, Au@UiO-66 was also reported as base-free catalyst for the oxidation of benzyl alcohol. ${ }^{70}$ The Au loading in Au@UiO-66 was $0.12 \mathrm{mmol} / \mathrm{g}$ and the particle size is $7 \mathrm{~nm}$ from HAADF-STEM analysis. On the other hand, XPS analysis revealed that Au@UiO-66 contains $87.7 \%$ of $A u(0)$ and $12.3 \%$ of $A u(I)$. This catalyst showed $94 \%$ conversion of benzyl alcohol with complete selectivity to benzaldehyde under oxygen atmosphere, although the time required is much longer and conversions ( $83 \%)$ achieved lower, when the reactions are carried out under air atmosphere. The Au/UiO-66 exhibits some decay upon reuse, with TON values for the first and second run of 35 and 28 and TOF values of $7.5 \mathrm{~h}^{-1}$ and $6 \mathrm{~h}^{-1}$, respectively. This decay seems not to be due to Au leaching or particle size growth, only 0.66 and $0.18 \%$ of Au was leached out during the first two runs 
and the TEM images indicated no significant change in the Au NP size distribution before and after catalysis. One possible explanation of the decay of the catalytic activity is based on the XPS spectrum of reused Au@UiO-66 that showed an increase of the peak associated to $\mathrm{Au}^{+}$ indicating a partial oxidation of metallic $\mathrm{Au}$ to $\mathrm{Au}^{+}$species during the catalytic tests and this change in the oxidation state could be reflected in a lower catalytic activity.
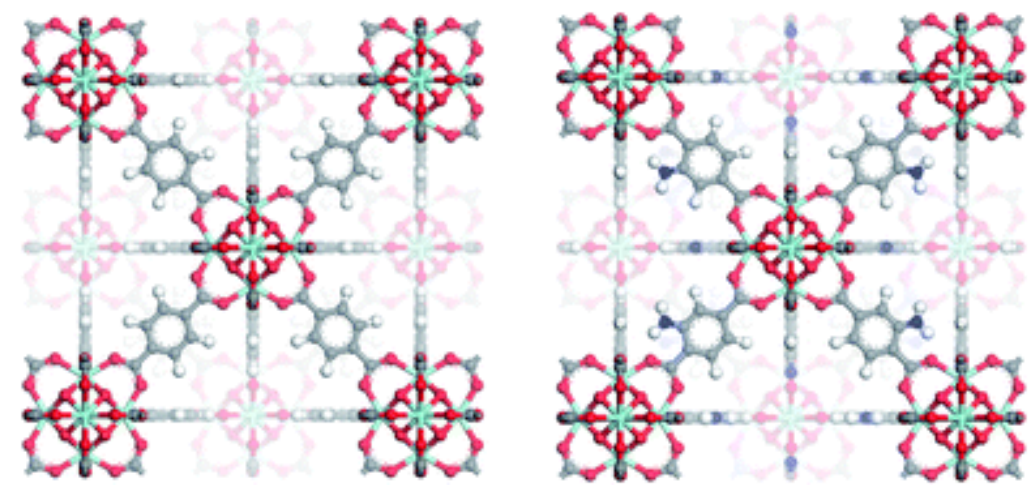

Figure 3. Structures of UiO-66 and $\mathrm{NH}_{2}-\mathrm{UiO}-66$ with 1,4-benzenedicarboxylate (BDC) as linker (left), and $\mathrm{NH}_{2}$-UiO-66 with 2-amino-1,4-benzenedicarboxylate as linker (right). Taken with permission from ref. ${ }^{95}$

As commented above, alcohol oxidation typically benefits from the presence of base. An elegant approach would be to encapsulate Au NPs inside a robust MOF that exhibits basicity due to the presence of $\mathrm{NH}_{2}$ substituent at the linker (see Figure 3 for crystal structure). As a realization of this idea, highly dispersed Au NPs have been immobilized on $\mathrm{NH}_{2}$-UiO-66 (Figure 4) to afford Au@NH $2-U i O-66$ and their catalytic activity examined in the base-free aerobic oxidation of benzyl alcohol. ${ }^{71}$ Similarly to the present UiO-66, the void space defined by the $\mathrm{NH}_{2}$-UiO-66 crystals has an octahedral geometry with a size of $150 \mathrm{~nm}$. Furthermore, HRTEM images after incorporation of $1.8 \mathrm{wt} \% \mathrm{Au}$ inside the pore of $\mathrm{NH}_{2}$-UiO66 revealed that the loading of $\mathrm{Au}$ NPs did not affect the nanomorphology of $\mathrm{NH}_{2}-\mathrm{UiO}-66$ crystals. As a result, Au NPs were highly dispersed on Au@NH $\mathrm{N}_{2}-\mathrm{UiO}-66$ particles with mean 
diameters of $2.8 \mathrm{~nm}$ and $3.1 \mathrm{~nm}$ (Figure 4), compatible with the cavity dimensions of $\mathrm{NH}_{2-}$ UiO-66 (3.6 nm). The EDX and XPS analyses confirm the existence of $\mathrm{Au}(0)$ inside $A u @ \mathrm{NH}_{2-}$ UiO-66. The powder XRD pattern of $\mathrm{NH}_{2}-\mathrm{UiO}-66$ coincides with that previously reported for this MOF in the literature, ${ }^{95}$ without loss of crystallinity in the process of Au encapsulation. Under the optimized reaction conditions, the use of $1.8 \mathrm{wt} \% \mathrm{Au@NH}_{2}-\mathrm{UiO}-66$ as catalyst gave $91 \%$ of benzaldehyde under base-free conditions in DMF after $1 \mathrm{~h}$ at $100{ }^{\circ} \mathrm{C}$. In contrast, the unsupported Au catalyst resulted in $5 \%$ yield of benzaldehyde under identical conditions. Even, addition of $\mathrm{Na}_{2} \mathrm{CO}_{3}$ only enhanced marginally the yield to $15 \%$, together with trace

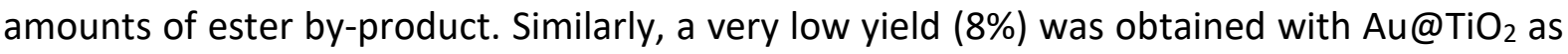
catalyst in the absence of $\mathrm{Na}_{2} \mathrm{CO}_{3}$ base and the addition of $\mathrm{Na}_{2} \mathrm{CO}_{3}$ boosted the yield using Au@ $\mathrm{TiO}_{2}$ as catalyst to $23 \%$. Furthermore, a slightly higher yield (23\%) was observed with Au@PANI (PANI: polyaniline) compared to Au@TiO 2 , which was attributed to the beneficial influence of the basicity of PANI. In this case also, the yield was increased to $31 \%$ by the addition of $\mathrm{Na}_{2} \mathrm{CO}_{3}$. All these data clearly indicate that the catalytic efficiency of $\mathrm{Au} @ \mathrm{NH}_{2}-$ UiO-66 is significantly higher under base-free conditions than any other alternative supported Au catalyst. Also, Au@NH $2-U i O-66$ is much more efficient than other reported analogous heterogeneous Au counterparts, ${ }^{96,97}$ which provide the desired benzaldehyde in $38 \%$ yield using the bulk Au catalyst and $9.2 \%$ yield using $\mathrm{Au} / \mathrm{MgO}$. The better catalytic performance of $\mathrm{Au} @ \mathrm{NH}_{2}-\mathrm{UiO}-66$ is explained by the high dispersion of Au NPs in a large surface area MOF support, exposing a large percentage of Au on the external surface of the Au NPs, and the narrow distribution of Au NPs without self-aggregation. Interestingly, in the case of $\mathrm{Au@N \textrm {N } _ { 2 } -}$ UiO-66, addition of a weak base, like $\mathrm{Na}_{2} \mathrm{CO}_{3}$ and $\mathrm{NaHCO}_{3}$ did not improve the yield. Even worse, it was also observed that the Au@ $\mathrm{NH}_{2}-\mathrm{UiO}-66$ catalyst tends to decompose slowly in the presence of the weak inorganic base. On the other hand, addition of strong base such as 
$\mathrm{NaOH}$ decomposed Au@ $\mathrm{NH}_{2}-\mathrm{UiO}-66$ catalyst, which finally resulted in a homogeneous solution. All the available catalytic data strongly suggest that the amino groups on the MOF linkers act as a weakly, but very efficient, basic promoter, allowing the occurrence of the efficient aerobic oxidation inside Au@NH $2-U i O-66$ without the addition of any external base (Figure 5). This is an interesting study and it is expected that will attract much attention in the future since numerous MOFs are unstable toward inorganic bases, ${ }^{94}$ but can possibly be synthesised having weak basic substituents on the organic linker. Furthermore, addition of 2,2,6,6-tetramethyl-piperidin-1-yl)oxyl (TEMPO) or azobisisobutyronitrile (AIBN) did not affect the reaction rate, supporting an anionic reaction pathway as indicated in Scheme 1 rather than radical autoxidation pathway. A marginal decrease in the yield of benzaldehyde was noticed after five reuses. However, ICP-AES analysis of the supernatant liquid showed no Au content. The powder XRD and FTIR spectra of Au@NH - -UiO-66 were similar to those of the fresh catalyst, showing the stability of the catalyst. It was, however, noted that SEM and TEM analyses indicate changes in the crystal nanomorphology of the as-synthesized catalyst after 5 cycles, showing some abrasion or corrosion of the crystals. As commented in section 5 , measuring the yield of the product at final reaction time in reusability experiments does not provide sufficient information to convincingly prove the absence of catalyst deactivation. In summary, it seems that the presence of weakly basic substituents in the organic linker makes unnecessary addition of an external base in certain alcohol oxidations, but additional information is needed to gain understanding in the deactivation mechanism. 

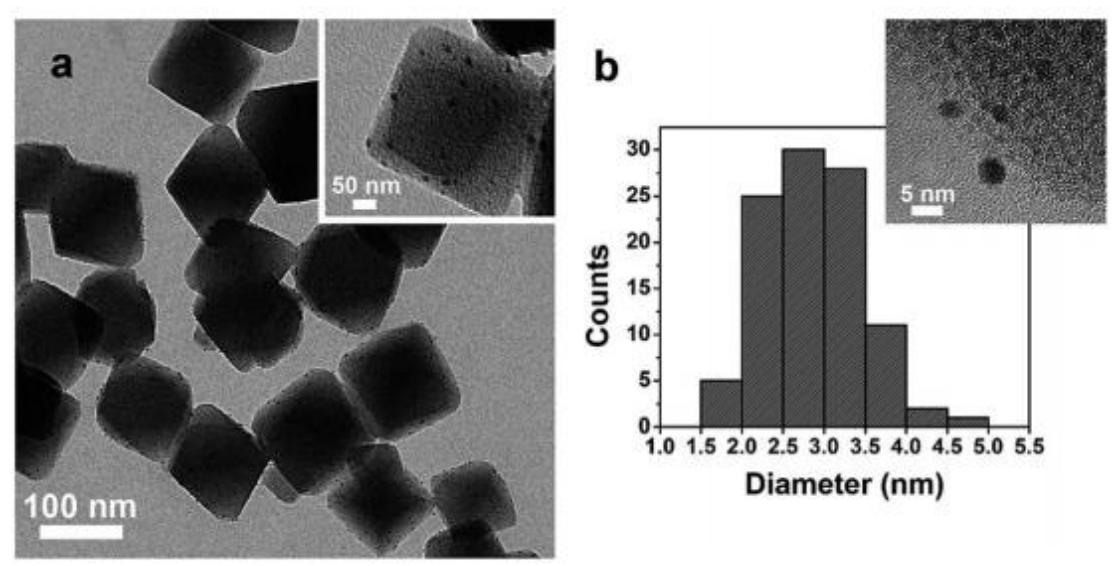

Figure 4. HRTEM images of 1.8\% Au@ $\mathrm{NH}_{2}-\mathrm{UiO}-66$ (a) and the corresponding size distribution of Au NPs (b). Insets of (a) and (b) showed zoomed TEM images. Taken with permission from ref. $^{71}$

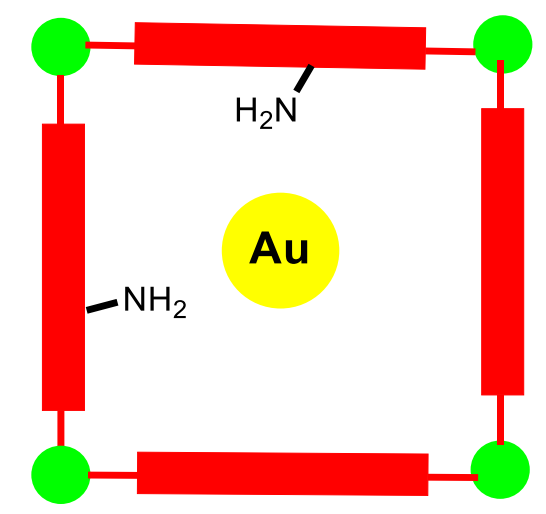

Figure 5. The presence of weakly basic amino groups on the aromatic linker near the encapsulated Au NPs makes unnecessary the addition of external bases on alcohol oxidation.

\section{Cycloalkane/Benzylic Oxidation}

Au NPs supported on different solids can exhibit distinct catalytic activity in the aerobic oxidation of cyclohexane. ${ }^{72}$ This reaction generally occurs through an autooxidation mechanism in which cyclohexyl radicals are the key intermediates that react with molecular oxygen, through a radical chain mechanism. As it can be seen in Table 2, Au NPs embedded on MOFs as supports are among the catalysts that exhibit the highest activity due to the chemical and structural diversity of the possible hosts. 
Thus, Au NPs have been supported on MIL-53(Cr) and MIL-101(Cr) and used as heterogeneous catalysts for the aerobic oxidation of cyclohexane. It was found that these MOF-encapsulated Au catalysts are stable and reusable catalysts for the aerobic oxidation of cyclohexane at $130{ }^{\circ} \mathrm{C}$ giving 23.3 and $24.1 \%$ conversion after $6 \mathrm{~h}$ for MIL-53(Al) and MIL101(Cr), respectively. ${ }^{72}$ The loading of $\mathrm{Au}$ in Au/MIL-53(Cr) and Au/MIL-101(Cr) was almost identical about $4.63 \mathrm{wt} \%$. TEM images indicate that the particles are highly dispersed on MIL$53(\mathrm{Cr})$ (square channels about $1.5 \mathrm{~nm}$ diagonal) with their size being $4.8 \pm 2.9 \mathrm{~nm}$, while in the case of MIL-101(Cr) (two types of cavities of 3.0 and $3.8 \mathrm{~nm}$ ) the particles are even smaller in the range of $1.8 \pm 0.6 \mathrm{~nm}$. Both catalysts were reused for five cycles with no decay in conversion and combined keto/ol mixture selectivity, but, however, no kinetic data were provided to confirm the catalyst stability in five cycles. The size of the Au NPs on the recovered sample did not show any agglomeration compared to that of the fresh catalyst. Furthermore, the same authors have found that in accordance with the literature, ${ }^{98} \mathrm{MIL}-101(\mathrm{Cr})$ has intrinsic activity to activate molecular oxygen forming reactive oxygen species able to promote autoxidation reactions. Therefore, it seems that MIL-101(Cr) is not an innocent host in this reaction, but it is also cooperating to the oxidation. Au/MIL-53(Cr) and Au/MIL-101(Cr) showed combined keto/ol mixture selectivity above $80 \%$, the highest for a given conversion among other catalysts under selected reaction conditions. Furthermore, the conversions of cyclohexane on these two catalysts are noticeably higher than for other catalysts including Au NPs-functionalized mesoporous silica. ${ }^{99}$

Table 2. Catalytic performance of Au catalysts with different supports. ${ }^{a}$ Data taken from the ref. ${ }^{72}$

\begin{tabular}{|l|l|l|l|l|}
\hline Catalyst & Conversion $^{\mathrm{b}}(\%)$ & $\begin{array}{l}\text { Keto/ol } \\
\text { selectivity }(\%)\end{array}$ & Keto/ol ratio $^{\mathrm{d}}$ & $\begin{array}{l}\text { Keto/ol yield } \\
(\%)\end{array}$ \\
\hline
\end{tabular}




\begin{tabular}{|c|c|c|c|c|}
\hline $\mathrm{Au} / \mathrm{TiO}_{2}$ & 21.4 & 64.0 & 1.69 & 13.7 \\
\hline $\mathrm{Au} / \mathrm{Y}-\mathrm{Fe}_{2} \mathrm{O}_{3}$ & 16.9 & 60.4 & 1.58 & 10.2 \\
\hline $\mathrm{Au} / \mathrm{ZSM}-5$ & 15.8 & 70.1 & 1.70 & 11.1 \\
\hline $\mathrm{Au} / \mathrm{MCM}-41$ & 18.8 & 71.6 & 1.74 & 13.5 \\
\hline $\mathrm{Au} / \mathrm{MIL}-96(\mathrm{Al})$ & 17.1 & 70.5 & 1.53 & 12.1 \\
\hline $\mathrm{Au} / \mathrm{MIL}-110(\mathrm{Al})$ & 17.2 & 69.3 & 1.58 & 11.9 \\
\hline $\mathrm{Au} / \mathrm{MIL}-53(\mathrm{Cr})$ & 31.3 & 81.9 & 1.81 & 25.6 \\
\hline $\mathrm{Au} / \mathrm{MIL}-101(\mathrm{Cr})$ & 30.5 & 87.7 & 2.05 & 26.7 \\
\hline
\end{tabular}

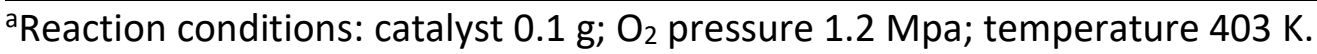

${ }^{b}$ Conversion was calculated on the basis of the initial and final amounts of cyclohexane. The standard deviations of conversions are less than $\pm 1.0 \%$.

'Selectivity was determined as the ratio of the yield of keto/ol mixture to the total yield of products. The standard deviations of selectivities are less than $\pm 1.0 \%$.

${ }^{d}$ Keto/ol mixture denoted as the molar ratio of cyclohexanone versus cyclohexanol.

Besides encapsulation of Au NPs, MOFs are also suitable hosts to incorporate the corresponding Au alloys with other metals. By alloying, MNPs with unique catalytic properties and morphologies can be obtained.

The combination of Pd modifying the activity of $\mathrm{Au}$ is something that has attracted considerable attention, since it can serve to develop unique catalysts frequently maintaining the high selectivity observed for Au catalysis, but with the high activity characteristic of Pd. Not surprisingly, Au-Pd alloys have also been incorporated inside MOFs and this host-guest system evaluated for its activity in cyclohexane and cyclohexene oxidation.

Au and Pd NPs obtained by colloidal method were dispersed on MIL-101(Cr) and their activity tested for the aerobic oxidation of cyclohexane. ${ }^{73}$ The powder XRD patterns of the $\mathrm{Au}-\mathrm{Pd} / \mathrm{MIL-101}(\mathrm{Cr})$ samples did not show any significant change with respect to that of the parent MIL-101(Cr) indicating the structural integrity of MIL-101 after MNP deposition. TEM characterization revealed that the Au-Pd NPs were homogeneously dispersed with narrow 
particle sizes ranging between 2 and $3 \mathrm{~nm}$ (average size: $2.40 \pm 0.63 \mathrm{~nm}$ ). TEM results indicated that $\mathrm{Au}$ and Pd formed mostly bimetallic alloys on the MIL-101. XPS data indicated that the existence of $\mathrm{Au}(0)$ and $\mathrm{Pd}(0)$ for the $\mathrm{Au}-\mathrm{Pd} / \mathrm{MIL}-101(\mathrm{Cr})(\mathrm{Au} / \mathrm{Pd}$ molar ratio $=1.4: 1)$. Under optimized mild, solventless reaction conditions, cyclohexane conversions higher than $40 \%$ with a TOF value of $19000 \mathrm{~h}^{-1}$ were reached with a combined selectivity to cyclohexanone and cyclohexanol of $95 \%$. In contrast, under identical conditions the corresponding physical mixture of $\mathrm{Au} / \mathrm{MIL}-101(\mathrm{Cr})$ and Pd/MIL-101(Cr) exhibited $28.4 \%$ conversion which is much lower value compared with the bimetallic alloy $\mathrm{Au}-\mathrm{Pd} / \mathrm{MIL}-101$ catalyst. The high activity and selectivity of Au-Pd/MIL-101 would derive from the synergistic alloying effect of bimetallic Au-Pd NPs. Au NPs are known to promote a variety of aerobic oxidations and Au clusters with high electron density exhibit higher activity for $\mathrm{O}_{2}$ activation with formation of peroxides. ${ }^{100,101}$ Therefore, the enhanced surface electron density revealed by XPS of bimetallic Au-Pd alloys as compared with monometallic Au should be favorable for $\mathrm{O}_{2}$ activation to form superoxo-like species $\left(\mathrm{O}_{2}^{-\bullet}\right) \cdot{ }^{100,101}$ The reaction profile showed an induction period for $20 \mathrm{~min}$ in which almost no conversion is observed. The presence of such an induction time was also observed in previous studies on liquid phase cyclohexane oxidation ${ }^{102}$ or benzylic autoxidation ${ }^{98}$ and can be attributed to the time needed to generate the first radicals, since it is well established that the liquid-phase aerobic oxidation of cyclohexane is a radical chain mechanism. In addition, it seems that the product cyclohexanone could also catalyze initiation steps of the autoxidation mechanism. ${ }^{103}$ It was observed that the reaction is almost fully suppressed by $p$-benzoquinone as quencher, giving a conversion of $\sim 2.3 \%$ after $4 \mathrm{~h}$ of reaction, thus, supporting the intermediacy of radical species also in the present catalytic system. This was further supported by analyzing the IR spectrum of the reaction mixture showing three peaks at 1308,1349 , and $1365 \mathrm{~cm}^{-1}$ that can be assigned to the 
vibrational modes of cyclohexyl hydroperoxide. ${ }^{104,105}$ No appreciable loss of conversion and selectivity was observed in the oxidation of cyclohexane in four consecutive runs, but initial reaction rates for each run were not measured. Powder XRD characterization showed also that the crystalline structure of MIL-101(Cr) was mostly retained. AAS experiments detected $<1 \%$ of the total Au or Pd in the reaction mixture. TEM images of the four times reused sample indicated a minimum aggregation of particles (average size: $2.59 \pm 0.51 \mathrm{~nm}$ ) in the material (Figure 6), still smaller than the MIL-101(Cr) cavity diameter. Therefore, the available data suggest that $\mathrm{Au}-\mathrm{Pd} / \mathrm{MIL}-101(\mathrm{Cr})$ could be a stable catalyst for this aerobic oxidation.
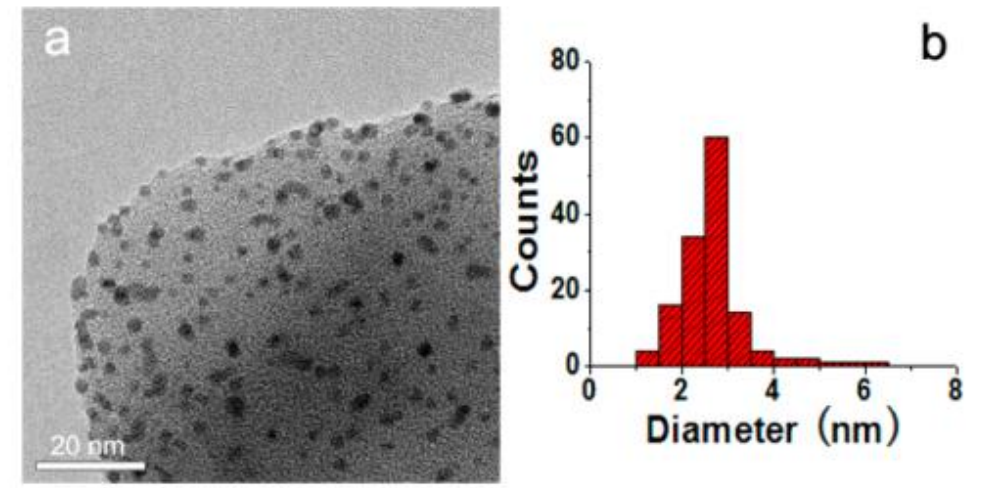

Figure 6. TEM image (a) of $\mathrm{Au}-\mathrm{Pd} / \mathrm{MIL}-101(\mathrm{Au} / \mathrm{Pd}$ molar ratio $=1.4: 1)$ after catalytic reaction and (b) the corresponding size distribution of Au-Pd NPs. The particle size distribution of AuPd alloys after exhaustive use as catalyst coincides with that of fresh material. Taken with permission from ref. ${ }^{73}$

Two particular features are important to understand performance of Au-Pd/MIL$101(\mathrm{Cr})$. The first one is that probably the solid is acting as initiator of the generation of the first cyclohexyl radicals, most likely by activation of molecular oxygen by formation of reactive oxygen species and, secondly, the remarkable product selectivity for such high cyclohexane conversion compared to analogous processes in homogeneous solution. The role of Au$\mathrm{Pd} / \mathrm{MIL}-101(\mathrm{Cr})$ as radical initiator rather than a true catalyst is compatible with the 
observation of an induction period, meaning that the material has not intrinsic activity, but it could have been supported by filtration of the solid catalyst at some conversion and allowing to continue the chain mechanism in the absence of $\mathrm{Au}-\mathrm{Pd} / \mathrm{MIL}-101(\mathrm{Cr})$ as initiator.

More important from the potential industrial use is perhaps the combined $95 \%$ selectivity to the keto/ol mixture at $40 \%$ cyclohexane conversion. In homogeneous phase using conventional organic radical initiators selectivity to keto/ol mixture decreases below $90 \%$ for cyclohexane conversion approaching $10 \%$. This high selectivity for aerobic oxidations involving cyclohexyl radicals has also been observed in other MOFs and has been attributed to the effect of confinement of the radical intermediates inside the pores of MOFs. ${ }^{98,106,107}$ In particular, it has been found that MOFs may have preferential adsorption for cycloalkanes respect to the corresponding keto/ol mixtures ${ }^{108}$ and, as a consequence, the space in where the reaction is taking place is enriched of starting material and impoverished of primary products resulting in preferential oxidation of the substrate even at conversions above $10 \%$. Scheme 3 illustrates this proposed influence of the polarity of MOF voids on the selectivity. It would be important to gain further understanding on the confinement effect that MOFs can play and to illustrate how this confinement effect can be applied to increase product selectivity of radical process that are notoriously unselective in homogeneous phase.

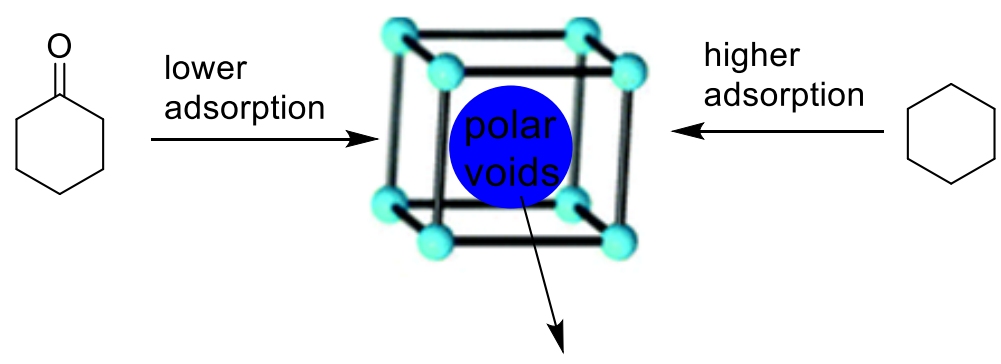

Chain radical oxidation occurring inside MOF voids 
Scheme 3. Proposal to rationalize the higher keto/ol selectivity of cyclohexane oxidation using Au-Pd NPs embedded within MOFs.

Therefore the existing data have satisfactorily established that Au NPs and their Pd alloys incorporated on structurally robust MOFs are general solids exhibiting sufficient stability to promote aerobic oxidation of cycloalkanes and to be reusable in consecutive runs. However, the role of these solids either as catalysts or as radical initiators of chain mechanism has not been sufficiently established. Considering the general autoxidation reaction mechanism, it is reasonable to assume that all the intermediates are common for conventional homogeneous radical initiators or when using MOFs as catalysts, with differences arising from the confinement of reaction intermediates and the chain length of the propagation steps.

Generally, Au catalysts are not able to promote aerobic oxidations of toluene and methylaromatics. However, in a seminal contribution, Hutchings and co-workers showed that $\mathrm{Au}-\mathrm{Pd} / \mathrm{TiO}_{2}$ can successfully promote the oxidation of toluene. ${ }^{109}$ In this way, Au-Pd with a particle size around $3 \mathrm{~nm}$ has been supported over MIL-101(Cr) as host [Au-Pd/MIL-101(Cr)], and its activity was investigated in the one-pot synthesis of aromatic esters through $\mathrm{C}-\mathrm{H}$ activation in methanol (Scheme 4). ${ }^{74} \mathrm{Au} / \mathrm{MIL}-101(\mathrm{Cr})$ exhibited only $1.4 \%$ conversion of toluene with $17 \%$ selectivity for methyl benzoate in good agreement with the low efficiency of $\mathrm{Au}$ catalysts to activate benzylic positions. A moderate conversion (34\%) with $88 \%$ selectivity of methyl benzoate was observed with a Pd/Au atomic ratio 1.5:1 in Au-Pd/MIL$101(\mathrm{Cr})$. This is apparently the optimal $\mathrm{Au}-\mathrm{Pd}$ ratio because a further increase in Pd content resulted in reduced selectivity (71.9\%) for methyl benzoate at similar conversion (33.8\%). An increase of the oxygen pressure results in higher toluene conversion $(50.5 \%)$, but remarkably reduced the selectivity to methyl benzoate $(71.5 \%)$. On the other hand, increasing the 
temperature to $120^{\circ} \mathrm{C}$ improved toluene conversion to $50.3 \%$, maintaining a high selectivity (84.2\%) for methyl benzoate under optimal conditions. A maximum of $96.9 \%$ toluene conversion was reached with $96.6 \%$ methyl benzoate selectivity at $\mathrm{Pd} / \mathrm{Au}$ atomic ratio of $1.5: 1$ at $120^{\circ} \mathrm{C}$ in $48 \mathrm{~h}$ using pure oxygen. Under optimized reaction conditions, the reaction between toluene and various aliphatic alcohols including methanol, ethanol, $\mathrm{n}$-propanol, and isopropyl alcohol afforded the corresponding esters with $96.9 \%, 99 \%, 94.5 \%$, and $92.8 \%$ conversions and $96.6 \%, 95.6 \%, 89.3 \%$, and $84.6 \%$ selectivities towards the expected esters, respectively. However, the yield of toluene oxidation and subsequent esterification decreased to $80.2 \%$ conversion with $80 \%$ selectivity for the reaction between toluene and $n$ butanol, suggesting a negative influence of the molecular size of the alcohol due to the steric hindrance. Au-Pd/MIL-101(Cr) was reused for three consecutive cycles, maintaining its structural integrity, but however, no kinetic data were given. The hot-filtration test confirmed the heterogeneity of the process, stopping the reaction upon filtration of the Au-Pd/MIL$101(\mathrm{Cr})$ solid at the reaction temperature. TEM images of the reused catalyst did not show any appreciable change in Au NP size after the reaction (Figure 7). Thus, all available characterization data support the stability of the Au-Pd/MIL-101(Cr) as catalyst in the aerobic oxidation of toluene. It should be commented that MIL-101(Cr) is one of the most robust MOFs that has been amply used as catalyst and the structural stability of MIL-101(Cr) lattice contributes to keep immobilized Au-Pd NPs avoiding their growth. Further studies are required to understand the reaction mechanism and the influence of the atomic ration of $\mathrm{Au}$ and $\mathrm{Pd}$ in promoting this reaction, although the increase in the electronic density of Au due to its higher electronegativity (2.54) respect to $\mathrm{Pd}(2.20)$ could be one of the reasons for a more efficient $\mathrm{O}_{2}$ activation. 
$\underset{\mathrm{CH}_{3} \mathrm{OH}, \mathrm{O}_{2}}{\stackrel{\mathrm{Au}-\mathrm{Pd} / \mathrm{MIL}-101(\mathrm{Cr})}{\longrightarrow}}$

Scheme 4. Synthesis of methyl benzoate from toluene catalyzed by Au-Pd/MIL-101(Cr).

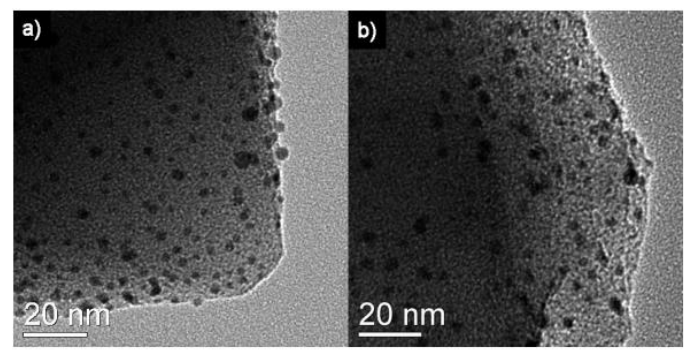

Figure 7. HRTEM images of 1 wt\% Au-Pd/MIL-101 a) before, and b) after the aerobic oxidation indicated in Scheme 4. Taken with permission from ref. ${ }^{74}$

Au-Pd/MIL-101(Cr) has also been used as catalyst for the aerobic oxidation of toluene and its derivatives in the absence of alcohols to the corresponding benzyl esters (Scheme 5). ${ }^{75}$ TEM images showed that the highly active Au-Pd systems have almost identical NP average sizes as those of single noble metal Pd- and Au-MIL-101(Cr), although the actual sizes were not reported. The catalytic activity of a series of $1 \mathrm{wt} \% \mathrm{Au}-\mathrm{Pd} / \mathrm{MIL}-101(\mathrm{Cr})$ catalysts with different Au-Pd molar ratios for the oxidation of toluene was screened. The maximum conversion was achieved using a $\mathrm{Pd} / \mathrm{Au}$ molar ratio of $1.5: 1$, reaching $98.6 \%$ of toluene conversion with $93 \%$ selectivity for benzyl benzoate. This optimal Pd/Au atomic ratio is about the same that has been found for other oxidations, including cyclohexane oxidation and formation of methyl benzoate previously commented. The TON of the optimal catalyst at 120 ${ }^{\circ} \mathrm{C}$ reached at $48 \mathrm{~h}$ was 986 . The reaction also produced small amounts of benzaldehyde and phenyl benzoate, although the presence of the presumable intermediates in the formation of benzyl benzoate such as benzyl alcohol and benzoic acid was not detected. The activity of 1 wt\% Au-Pd/MIL-101(Cr) is superior to the analogous catalysts, namely, Au-Pd/C (TON of 690), 
which is among the most active catalysts for toluene oxidation ever reported. ${ }^{109} \mathrm{Au}-\mathrm{Pd} / \mathrm{MIL}-$ $101(\mathrm{Cr})$ was also found to be a highly efficient catalyst for the oxidation of a range of methylaromatics including xylenes, 2-, 3-, and 4-methoxytoluene and 4-fluorotoluene. A TON of 1206 was obtained in the oxidation of $p$-xylene to the corresponding substituted benzaldehyde, benzyl benzoate and phenyl benzoate at $120{ }^{\circ} \mathrm{C}$ using Au-Pd/MIL-101(Cr). Similarly, oxidation of substituted toluenes resulted in the formation of the corresponding benzyl esters as the major products with an overall selectivity $>80 \%$, without observing the presence of aromatic carboxylic acids or the formation of $\mathrm{CO}_{2}$. $\mathrm{Au}-\mathrm{Pd} / \mathrm{MIL}-101$ was found to be stable and reusable for three cycles, showing negligible metal leaching or aggregation and maintaining its crystalline structure as evidenced by powder XRD.

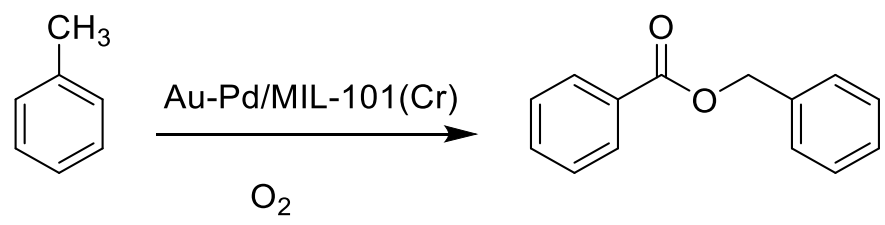

Scheme 5. Au-Pd/MIL-101(Cr) mediated synthesis of benzyl benzoate from toluene.

As a general statement of the current state of the art, it can be concluded that, once again, incorporation inside the pores of structurally robust MIL-101(Cr) of Au-Pd alloys results in a catalyst enjoying wide scope, higher activity, stability and reusability for the selective toluene oxidation by oxygen. It remains to be studied in deeper detail whether core@shell structuring or true alloys at the nanoscale are more efficient for this type of oxidations.

Highly dispersed Au NPs were supported on UiO-66 and their activity were evaluated for CO oxidation. ${ }^{76}$ Comparison of powder XRD patterns of UiO-66 and Au@UiO-66 confirmed that the integrity of the UiO-66 framework is maintained during Au NP immobilization. On the other hand, TEM images revealed that the particle size has a mean diameter of $2.8 \pm 0.5 \mathrm{~nm}$. The catalytic performance of Au@UiO-66 was evaluated in gas-phase CO oxidation using a 
fixed-bed flow reactor, observing the $\mathrm{CO}$ conversion as a function of temperature. For example, the temperatures to reach $50 \%$ conversion were approximately 175, 165, and 155 ${ }^{\circ} \mathrm{C}$, respectively, for 1.5, 2.8, and 4.0 wt \% Au loading in Au@UiO-66 samples, which are lower to those reported for Au@ZIF-8 which requires $225,200,185$, and $170{ }^{\circ} \mathrm{C}$, respectively, for $0.5,1.0,2.0$ and $5.0 \mathrm{wt} \%$ samples. ${ }^{110}$ It is known in the state of the art that the catalytic activity of Au NPs for the low temperature, selective CO oxidation depends on the particle size, dispersion of Au atoms on the external surface of NPs and nature of the support. ${ }^{31,32,34}$ Thus, the higher catalytic activity of Au@UiO-66 respect to Au@ZIF-8 is probably due to the same reasons. No significant decrease in catalytic activity was noticed after five runs for CO oxidation for all the Au@UiO-66 samples examined, thus, confirming their stability under the optimized reaction conditions. On the other hand, reporting initial reaction rates upon reuse would have provided better support of catalyst stability.

\section{4-Nitrophenol Reduction}

Catalytic reduction of 4-nitrophenol to 4-aminophenol by $\mathrm{NaBH}_{4}$ or other reducing agents in water is one of the favourite test reactions to evaluate the activity of different Aucontaining materials. The reaction course can be conveniently followed by absorption optical spectroscopy monitoring the disappearance and growth of the characteristic bands of the substrate and product, respectively. The general mechanism is presented in Scheme \# and is believed to involve adsorption of nitrophenol on Au NPs through the nitro group and formation of Au-H from $\mathrm{BH}_{4}{ }^{-}$.(Zhao, P. X.; Feng, X. W.; Huang, D. S.; Yang, G. Y.; Astruc, D., Basic Concepts and Recent Advances in Nitrophenol Reduction by Gold- and Other Transition Metal Nanoparticles. Coord. Chem. Rev. 2015, 287, 114-136.) 


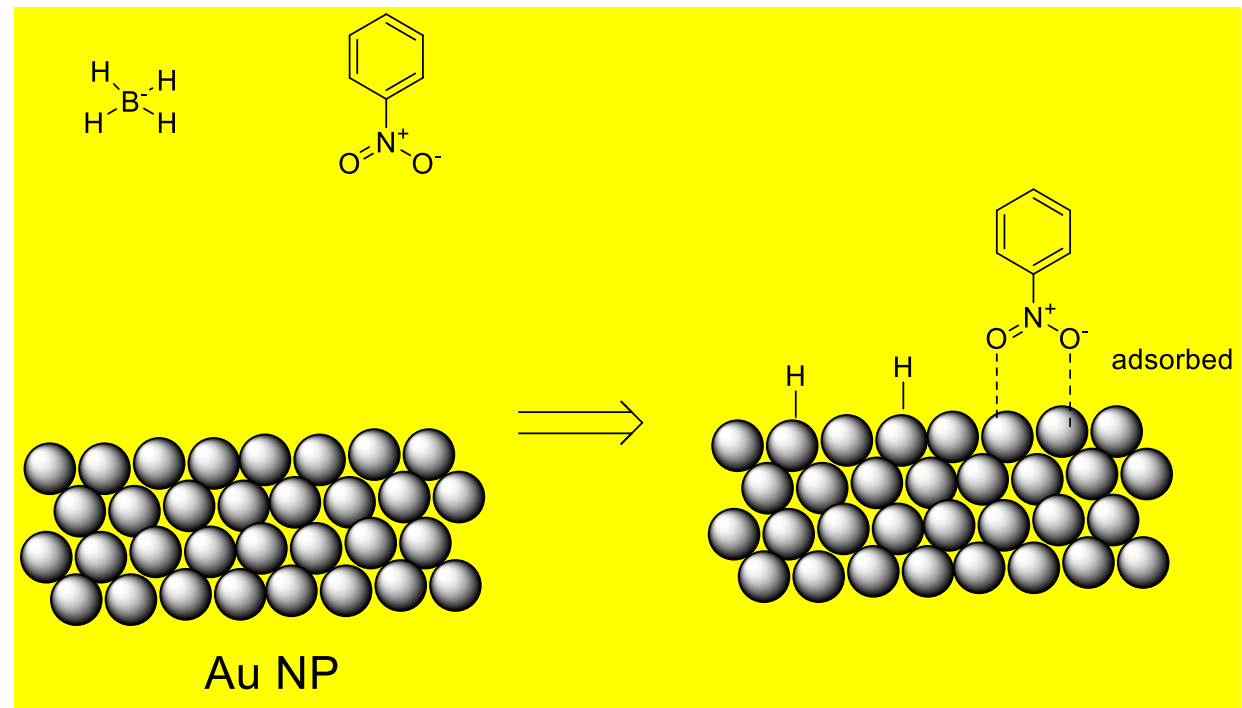

Scheme \#. General reaction mechanism for the Au catalized reduction of nitro aromatics.

When the reaction is carried out in large excess of reductant, then, the kinetics is pseudo first order and the corresponding rate constants give a quantitative estimation of the catalytic activity. In this way, comparison of the $\mathrm{k}$ values can serve to determine the influence that MOF lattice embedding Au NPs can play on the catalytic activity. Reduction of aromatic nitro compounds like 4-nitrophenol and 2,4-dinitrophenol has also attracted a continued interest primarily to transform them due to their explosive nature as well as their severe environmental negative effects. ${ }^{111}$ On the other hand, their reduced products are widely employed for the synthesis of dyes and other various applications. ${ }^{112,113}$

As indicated briefly in the introduction, instead of having Au NPs embedded within the pores of a MOF host, an alternative possibility that could have similar benefits is the coating of Au NPs by a thin shell of the MOF. In one realization of this idea, a porous Au@MIL-100(Fe) core-shell nanocatalyst with controllable MIL-100(Fe) shell thickness was prepared and its activity examined in the reduction of 4-nitrophenol. ${ }^{77}$ The powder XRD pattern of the assynthesized Au@MIL-100(Fe) NPs shows the peaks corresponding to both Au and MIL- 
100(Fe). The TEM images indicate that these NPs have core-shell structures in where the core is $\mathrm{Au}$ and the shell is MIL-100(Fe), while the SEM images show that the thickness of the shell is around $60 \mathrm{~nm}$ in diameter. The complete reduction of 4-nitrophenol was achieved within 15 min with Au@MIL-100(Fe) as catalyst, while pure Au (220 min) and MIL-100(Fe) (110 min) NPs required longer time. Significantly, the k value for the Au@MIL-100(Fe) catalyst was 0.33 $\min ^{-1}$, which is twenty and ten times higher than for pure Au and MIL-100(Fe) NPs, respectively. This enhanced activity may be attributed to the synergistic effect of the Au and MIL-100(Fe). ${ }^{114}$ It is proposed that this synergy arises from the adsorption of 4-nitrophenol over the MIL-100(Fe) shell giving rise to a local high concentration of 4-nitrophenol. This high concentration of nitrophenol on MIL-100(Fe) increases the contact probability with Au as active site and, thus, enhances the catalytic efficiency of the system for the 4-nitrophenol reduction (Scheme 6). No significant loss of activity for the reduction of 4-nitrophenol was observed for Au@MIL-100(Fe) in five successive cycles, the powder XRD pattern confirming the structural integrity of Au@MIL-100(Fe). It is worth commenting the intrinsic catalytic activity observed for MIL-100(Fe), that is, in fact, widely employed for the reduction of nitrophenol. ${ }^{80,81}$ Thus, this type of $\mathrm{MIL}-100(\mathrm{M})(\mathrm{M}=\mathrm{Fe}$ or $\mathrm{Cr}$ ) materials are active solid catalysts for $\mathrm{NaBH}_{4}$ reductions. ${ }^{67}$

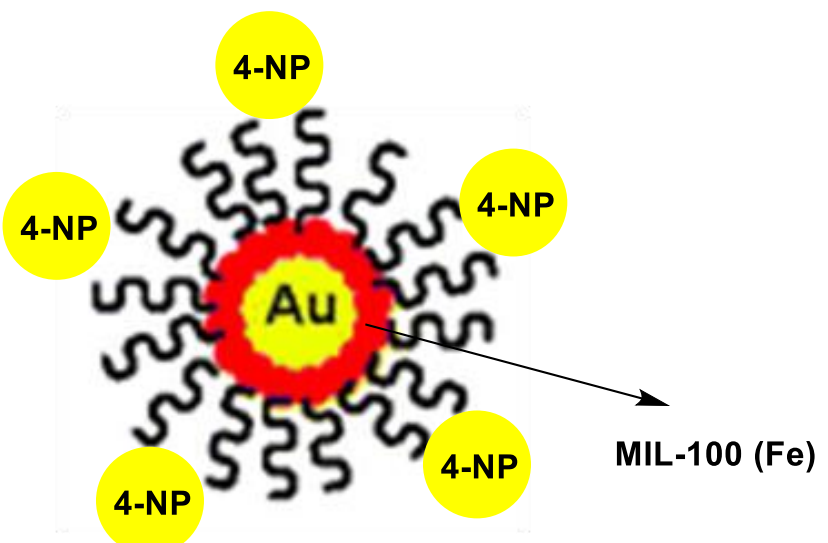

Scheme 6. Proposed mechanism for the reduction of 4-nitrophenol by Au@MIL-100(Fe). 
The reduction of 4-nitrophenol by $\mathrm{NaBH}_{4}$ at room temperature was selected to study the activity of Au@NH2-UiO-66 catalyst. ${ }^{71}$ The highly dispersed Au NPs on $\mathrm{NH}_{2}-\mathrm{UiO}-66$ exhibited an excellent catalytic activity for the reduction of 4-nitrophenol to 4-aminophenol, the reaction being completed within $9 \mathrm{~min}$ in the presence of $1.8 \%$ Au@NH $2-\mathrm{UiO}-66 .{ }^{71}$ In contrast, the reduction reaction did not proceed in the absence of the catalyst or in the presence of only the $\mathrm{NH}_{2}-\mathrm{UiO}-66$ material. This clearly demonstrates the role of Au NPs in the reduction reaction. No data was given on the stability of this catalyst.

A $\mathrm{Cu}(\mathrm{II})-\mathrm{MOF}$ consisting a three-fold interpenetrated NbO-type network with nanosized hexagonal channels and distance between opposite $\mathrm{Cu} \cdots \mathrm{Cu}$ in the channel of $2.29 \mathrm{~nm}$ was used as host to incorporate Au NPs (Figure 8). ${ }^{115}$ The resulting Au@Cu(II) MOF material was tested for the reduction of 4-nitrophenol, and a tandem reaction involving oxidation of benzyl alcohol followed by Knoevenagel condensation. ${ }^{78}$ The $\mathrm{Au}$ content measured by ICP analysis was $9.38 \mathrm{wt} \%$ and XPS analysis showed the existence of metallic Au. HRTEM images showed that Au@Cu(II) MOF contains monodisperse Au NPs with approximately spherical shape and an average particle size of ca. $2 \mathrm{~nm}$ without observable aggregation. The TON and TOF values for the reduction of 4-nitrophenol were 1000 and 2000 $\mathrm{h}^{-1}$. HRTEM and powder XRD patterns demonstrated that the particle size of Au NPs and crystallinity of the MOF, respectively are maintained after the reaction, but however, no data were found on long term stability of this catalyst. 


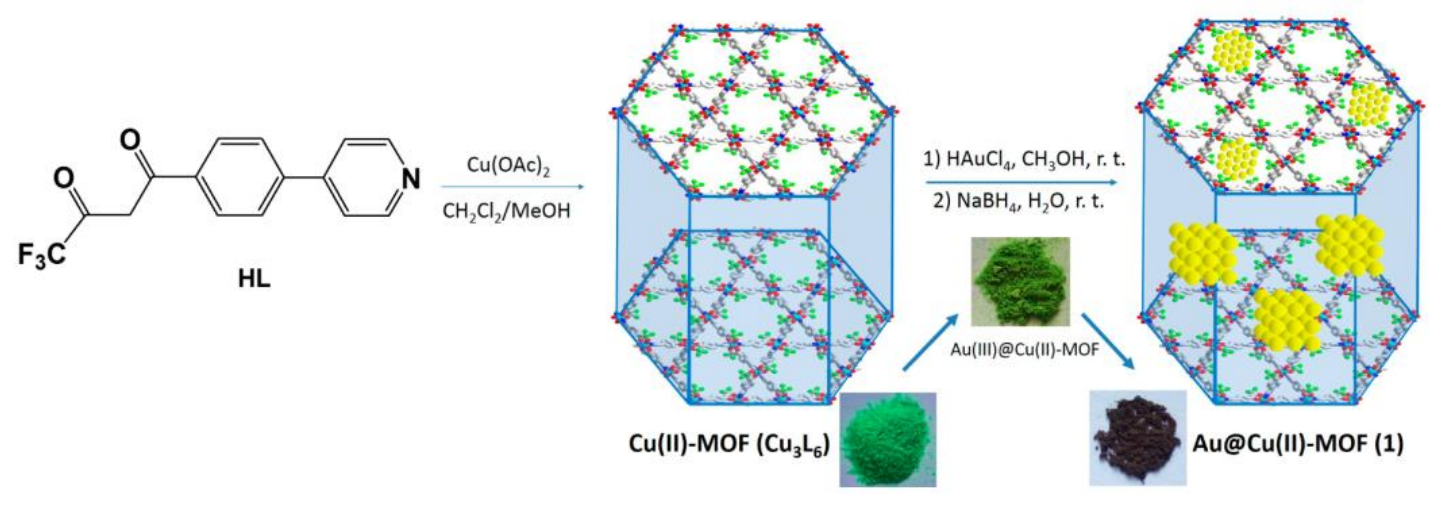

Figure 8. Deposition of Au NPs within the pores of $\mathrm{Cu}(\mathrm{II})$-MOFs. Taken with permission from ref. $^{78}$

It is well known in organometallic chemistry that positive $\mathrm{Au}^{+/ 3+}$ ions form strong complexes with terminal alkynes. ${ }^{116}$ Also, Au NPs are known to strongly bind to terminal alkynes. ${ }^{117,118}$ In an elegant application of this tendency to establish strong interactions between Au species and alkynes, MOFs with linkers having pendant terminal alkynes have been synthesised and used as host of Au NPs.

Solvothermal reactions of 5-(prop-2-yn-1-yloxy)isophthalic acid and $\mathrm{Zn}\left(\mathrm{NO}_{3}\right)_{2} \cdot 6 \mathrm{H}_{2} \mathrm{O}$ with various 4,4'-bipyridyl derivatives result in the synthesis of several MOF structures named as MOF-1, MOF-2 and MOF-3 having different porosity. ${ }^{79}$ In all these frameworks, the dicarboxylic acid moiety of the ligand formed 2D layered networks connecting distorted octahedral $\mathrm{Zn}^{2+}$ ions. These 2D layers are interconnected to each other by $4,4^{\prime}$-bipyridyl linkers via coordination with the axial positions of the octahedral $\mathrm{Zn}^{2+}$ ions to render 3D MOFs with porous channels. Figure 9 shows the structure of the resulting Zn MOFs and the presence of pendant terminal alkynes. Single-crystal X-ray diffraction analyses of MOF-1 and MOF-2 revealed that both structures are nearly isostructural. Using these MOF 1-3 as hosts, it was possible to include as much as $49.3 \pm 0.4 \mathrm{wt} \%$ of Au loading. The size distribution of Au particle 


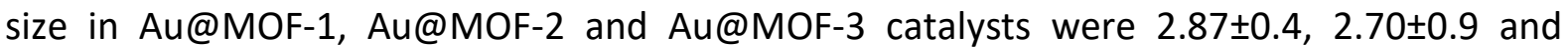
$1.85 \pm 0.3 \mathrm{~nm}$, which indicated remarkably high monodispersity of the samples in spite of the high Au loading. Powder XRD confirmed the preservation of MOF structure after loading of Au-NPs and XPS showed the existence of $A u(0)$. To establish whether the alkyne moieties of the ligands actually have any distinct role in stabilizing the $\mathrm{Au}^{3+}$ ions or Au-NPs, a structurally similar MOF-A (5 wt\%) functionalized with phenyl moieties instead of ethynyl groups was prepared as control and used also as catalyst. In the case of Au@MOF-A, TEM images revealed the agglomeration of Au particles with a particle size $>12 \mathrm{~nm}$. The 4-nitrophenol reduction reactions were completed within $3 \mathrm{~min}$ in the presence of Au@MOFs as catalysts (Table 3$)^{79}$ which is much faster than the reactions with $\mathrm{NaBH}_{4}$ and $\mathrm{HAuCl}_{4}$ itself and even faster than earlier reports on MOFs supported Au NPs. ${ }^{77,82}$ Although Au NPs have different sizes in these Au@MOFs, no clear relationship between average Au particle size and catalytic activity can be deduced and, therefore, deeper understanding of the origin of the catalytic activity and the factors controlling catalyst performance is still necessary. In any case, the TON and TOF values indicate comparatively better activity of Au@MOF with respect to other catalytic systems. The stability of the Au@MOF catalysts was established by TEM after the reactions and the high monodispersity of NPs clearly support that the strong interaction between Au and MOF network through the functionalized ethynyl moiety is playing a positive role controlling the stability of encapsulated Au NPs. Although the stability of Au@MOF-3 catalyst was studied by reusing it for five times as well as analyzing the five times reused catalysts by powder XRD and TEM, no kinetic data were provided regarding the initial reaction rates, which will confirm catalyst stability under the reaction conditions for the reuses. 


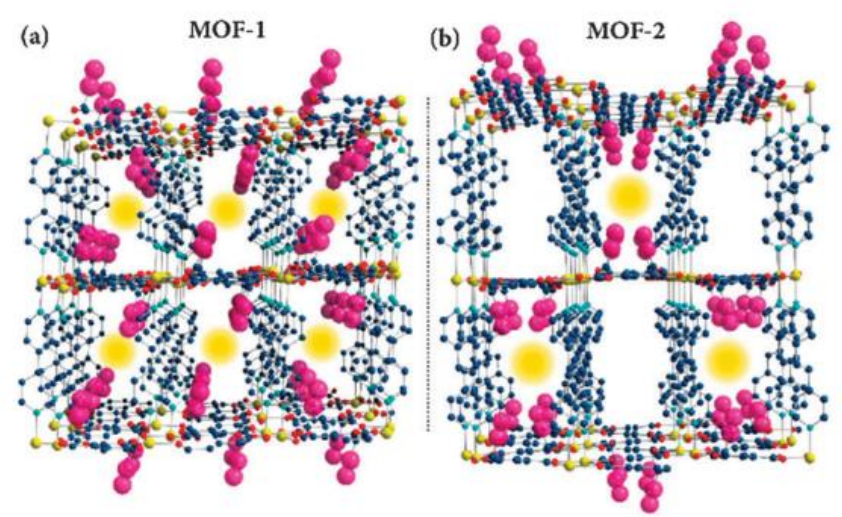

Figure 9. Crystal structures of MOF-1 and MOF-2. (a) Extended three dimensional network of MOF-1 showing channel-like pores. Each pore is decorated with functionalized alkyne moieties. (b) The alternate pores are functionalized with alkyne moieties in MOF-2. The alkyne moieties are highlighted in pink color. Color codes: yellow, cyan, navy blue and red represent $\mathrm{Zn}, \mathrm{N}, \mathrm{C}$ and $\mathrm{O}$, respectively. Taken with permission from ref. ${ }^{79}$

Table 3. Estimated rate constants for the MOF-encapsulated Au NPs catalyzed reduction of 4nitrophenol and 2,4-dinitrophenol. Data taken from ref. ${ }^{79}$

\begin{tabular}{|l|l|l|l|}
\hline & \multicolumn{2}{l|}{ Rate constant $\left(\mathrm{s}^{-1}\right)$} \\
\hline Substrate & Au@MOF-1 & Au@MOF-2 & Au@MOF-3 \\
\hline 4-Nitrophenol & $6.64 \times 10^{-2}$ & $5.92 \times 10^{-2}$ & $6.88 \times 10^{-2}$ \\
\hline $2,4-$ dinitrophenol & $2.99 \times 10^{-2}$ & $2.46 \times 10^{-2}$ & $2.90 \times 10^{-2}$ \\
\hline
\end{tabular}

The simplicity in which the course of 4-nitrophenol reduction can be followed allows the easy evaluation of complex catalytic systems in which besides Au NPs and MOFs, other components can be present to facilitate catalyst recovery or improve the performance. In this way, a MOF based porous magnetic core-shell Au catalyst, namely, Au-Fe $\mathrm{O}_{4} @ \mathrm{MIL}-100(\mathrm{Fe})$ was synthesised by a series of consecutive steps starting from $\mathrm{Fe}_{3} \mathrm{O}_{4}$, forming $\mathrm{Au}$ NPs and coating them with MOF prepared by layer-by-layer $\mathrm{Fe}^{3+}, \mathrm{BTC}$ assembly (Figure 10). Magnetic $\mathrm{Fe}_{3} \mathrm{O}_{4}$ core allows for a fast recovery of the catalyst using magnets. The activity of these 
magnetic core-shell Au catalyst was tested in the reduction of 4-nitrophenol. ${ }^{80}$ Representative HRTEM images of Au-Fe $\mathrm{O}_{4} @ M I L-100(\mathrm{Fe})$ show the existence of Au NPs with diameters in the range of 3-5 nm. The core-shell Au- $\mathrm{Fe}_{3} \mathrm{O}_{4} @ \mathrm{MIL}-100(\mathrm{Fe})$ magnetic catalyst in which the MOF layer was prepared by 5 assembly cycles exhibited the highest activity with a rate constant of $5.53 \mathrm{~min}^{-1}$, which is 2 and 168 times higher than that of $\mathrm{Au}-\mathrm{Fe}_{3} \mathrm{O}_{4}$ and MIL-100(Fe), respectively. These activity data show that the catalytic efficiencies are higher for Au catalysts confined in MOF shells with ordered mesopores. The catalyst was reused in five successive cycles, although it was observed that conversion of 4-nitrophenol dropped by $20 \%$ and the rate constant value decreases from 5.53 to $1.57 \mathrm{~min}^{-1}$. In the previous sections dealing with benzyl alcohol oxidation as well as in the current one focused on nitrophenol reduction, the use of stable and robust MIL solids as hosts had led to the development of Au catalysts exhibiting the highest activity that in general terms can be attributed to the high dispersions of small size Au NPs within the host pores and the synergy arising from local substrate concentration. However, the fact that in present case the stability of $\mathrm{Au}-\mathrm{Fe}_{3} \mathrm{O}_{4} @ \mathrm{MIL}-100(\mathrm{Fe})$ is not satisfactory raises the issue of the reasons for the observed deactivation and if there are ways to circumvent this decay recovering the activity of fresh material.

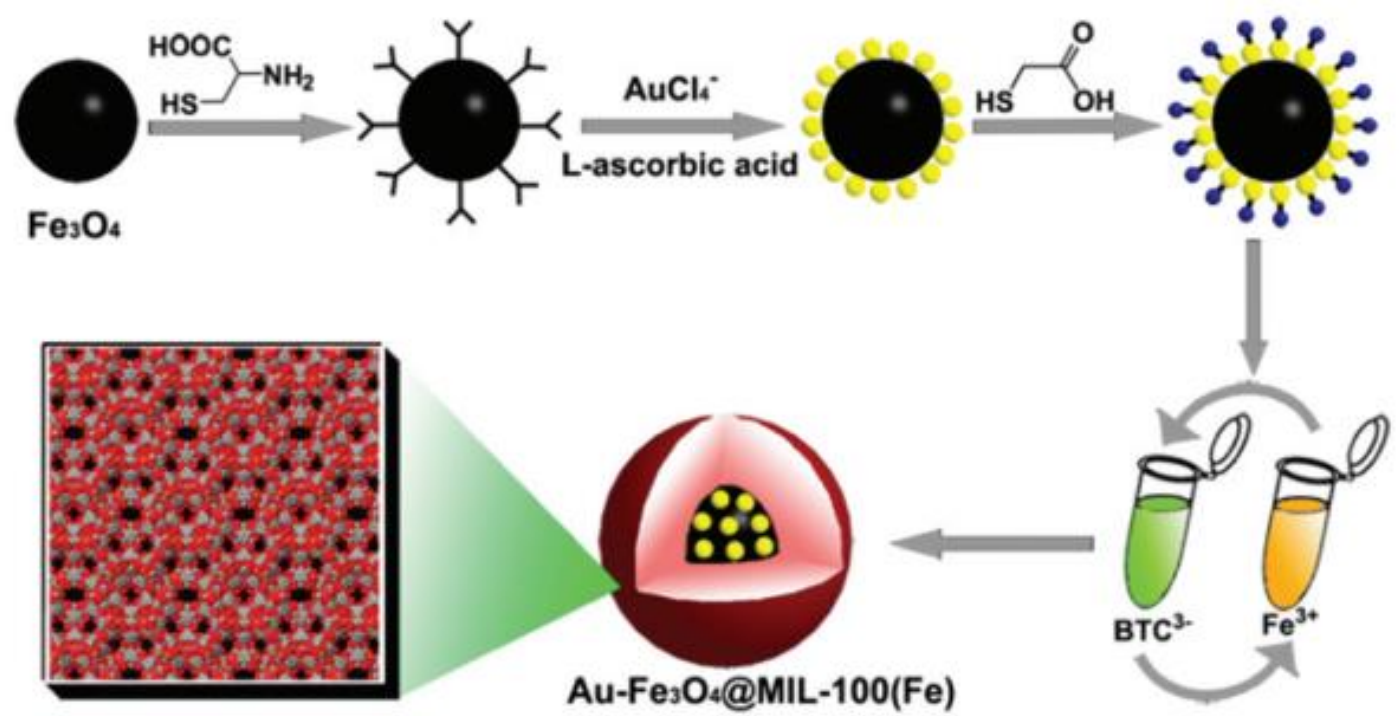


Figure 10. Preparation of the $\mathrm{Au}-\mathrm{Fe}_{3} \mathrm{O}_{4} @ \mathrm{MIL}-100$ (Fe) core-shell magnetic NPs by layer-bylayer synthesis. The Au NPs were first immobilized on the surface of L-cysteine modified $\mathrm{Fe}_{3} \mathrm{O}_{4}$ NPs using L-ascorbic acid as the reducing agent, followed by functionalizing with mercaptoacetic acid (MAA). Then, the Au- $\mathrm{Fe}_{3} \mathrm{O}_{4} @ \mathrm{MIL}-100(\mathrm{Fe})$ core-shell catalyst was prepared by repeated cycles of dispersing the MAA-functionalized $\mathrm{Au}-\mathrm{Fe}_{3} \mathrm{O}_{4}$ NPs separately into the ethanol solutions of $\mathrm{FeCl}_{3}$ and $\mathrm{H}_{3} \mathrm{BTC}$ at $70{ }^{\circ} \mathrm{C}$. The overall shell thickness can be controlled by adjusting the assembly cycle number. Taken with permission from ref. ${ }^{80}$

In a further example of multifunctional composites, Au-loaded magnetic MOFs/graphene ( $\mathrm{rGO} @ \mathrm{Fe}_{3} \mathrm{O}_{4} @ \mathrm{MIL}-100 / \mathrm{Au}$ ) was prepared by coating $\mathrm{Fe}_{3} \mathrm{O}_{4}$ NPs supported on rGO with MIL-100 using layer by layer synthesis and final incorporation of Au NPs (Figure 11). The role of $\mathrm{rGO}$ should be to increase the catalytic activity by facilitating substrate adsorption. The activity of $\mathrm{rGO} @ \mathrm{Fe}_{3} \mathrm{O}_{4} @ \mathrm{MIL}-100 / \mathrm{Au}$ was evaluated in the reduction of 4nitrophenol to 4-aminophenol. ${ }^{81}$ TEM images reveal that the size of $\mathrm{Fe}_{3} \mathrm{O}_{4} \mathrm{NPs}$ dispersed on $\mathrm{rGO}$ is in the range $35-55 \mathrm{~nm}$ and that the surface of $\mathrm{Fe}_{3} \mathrm{O}_{4} \mathrm{NPs}$ is well-encapsulated by MIL100(Fe) shells. The sizes of Au NPs are mainly in the range of 1-8 $\mathrm{nm}$, with an average diameter about $3 \mathrm{~nm}$. The rate constant for 4-nitrophenol reduction using rGO@Fe $\mathrm{O}_{4} @ M I L-$ $100(\mathrm{Fe}) / \mathrm{Au}$ as catalyst was $2.52 \mathrm{~min}^{-1}$. Interestingly, this value is much larger than some other catalysts as, for instance, the value of $0.266 \mathrm{~min}^{-1}$ for $\mathrm{Au} @$ polypyrrole/ $/ \mathrm{Fe}_{3} \mathrm{O}_{4}$ hollow capsules, $^{119} 0.37 \mathrm{~min}^{-1}$ for Au@polyphenol metal nanocomposites, ${ }^{120} 0.19 \mathrm{~min}^{-1}$ for Au/graphene hydrogels, ${ }^{121}$ and $0.48 \mathrm{~min}^{-1}$ for Au/PMMA (PMMA: polymethyl methacrylate). ${ }^{122}$ This superior catalytic performance can be ascribed to the high loading of MNPs while still achieving a small size and high dispersability. Although the catalytic activity 
remains stable even after 10 cycles, and the conversion of each cycle remains nearly $95 \%$, temporal profiles of substrate consumption and product formation should have been provided for each cycle to prove catalyst stability without any deactivation. In addition, no changes were found in the XPS of the composite after 10 reduction cycles which is in support of the claimed high stability. The ICP-AES analysis indicated that $85 \%$ of initial Au content was maintained on the catalyst even after 10 cycles. It should be noted that in this system Au NPs are not exclusively located inside the MIL-100(Fe) shell surrounding magnetic $\mathrm{Fe}_{3} \mathrm{O}_{4} \mathrm{NPs}$, but they are also supported directly on rGO. It would be important to determine what is the relative contribution of MIL-100 encapsulated Au NPs with respect to rGO supported Au NPs. Thus, some improvements in the preparation procedure are still necessary to obtain samples where Au NP location is better defined.

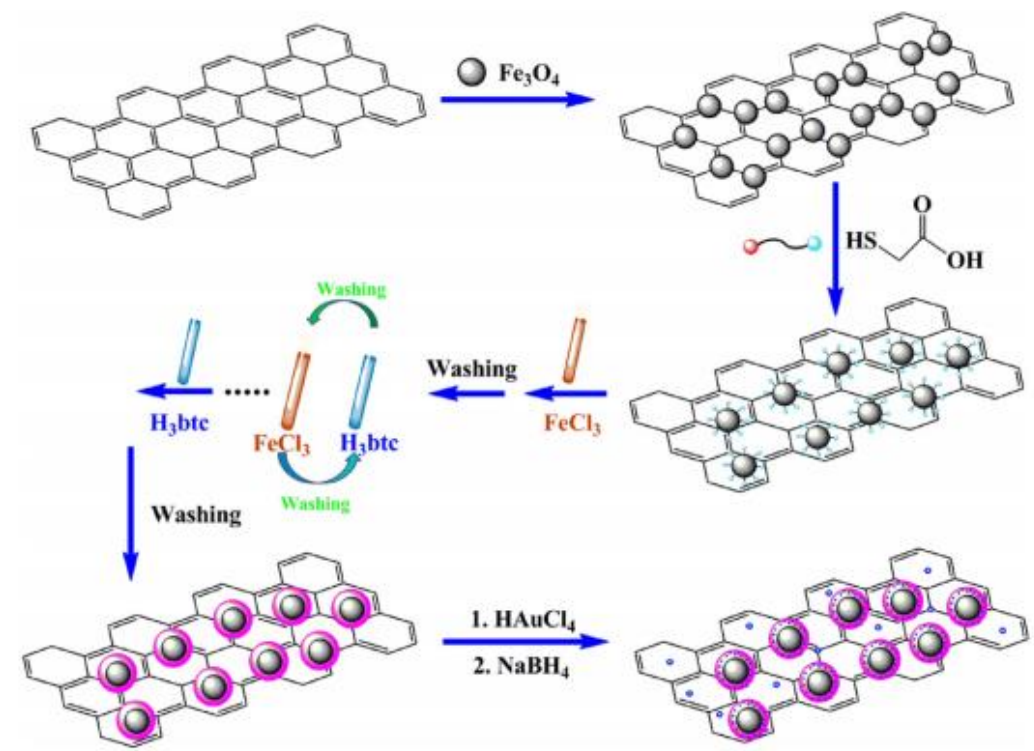

Figure 11. Schematic illustration of the preparation process of $\mathrm{rGO} @ \mathrm{Fe}_{3} \mathrm{O}_{4} @ \mathrm{MIL}-100$ (Fe)/Au. Taken with permission from ref. ${ }^{81}$

In addition to real alloys with a random distribution of metal atoms, other possibilities that have been reported are core-shell in where one metal is located at the centre of the NPs and the second one at the outer part. In a simplistic way, core-shell MNPs exhibit similar 
catalytic activity to that of the pure MNPs of the metal present at the shell, but tuned in activity and selectivity by the metal of the core that can be considered that influences the property of the shell by inductive effects, decreasing or increasing the electronic density of the shell metal. In of these examples, ZIF-8 has been used as host to encapsulate Au-Ag alloys.

In one of these studies aimed at determining the catalytic activity of MOFencapsulated Au NPs, Au-Ag core-shell NPs were deposited on ZIF-8 by a sequential deposition-reduction procedure. ${ }^{82}$ Two alternative approaches were used changing the order in which the metal salts are reduced (Figure 12). Au@Ag core-shell NPs on ZIF-8 were prepared at different weight percentage of Au and Ag with respect to ZIF-8. Bimetallic Au and Ag NPs embedded on ZIF-8 were tested for the catalytic reduction of 4-nitrophenol to 4aminophenol by $\mathrm{NaBH}_{4}$ in water. As controls, the reaction did not occur over a 2 wt\% Au@ZIF8 catalyst and proceeds slowly with observation of an "induction period" over a 2 wt\% Ag@ZIF-8 catalyst. The catalytic activity was significantly improved by using Au-Ag core-shell as catalysts. Among all these catalysts studied, the catalyst that was prepared following the approach II in Figure 12 at 2 wt\% of Au and Ag has the highest activity with an estimated rate constant of $4.97 \times 10^{-3} \mathrm{~s}^{-1}$, which is superior to that of most Au- and Ag-based catalysts under ambient conditions. Moreover, the catalyst was reusable in three consecutive runs by monitoring the course of the reaction by UV-Vis absorption spectroscopy, thus, proving its stability, which was confirmed further by the TEM images. In contrast, the activity of 2 wt\% of $\mathrm{Au}$ and $\mathrm{Ag}$ prepared via approach I in Figure 12 greatly decreased after being subjected to oxidation and reduction treatments at elevated temperatures, due to the formation of a true Au-Ag alloy with a NP size of around 3-8 $\mathrm{nm}$ that are larger than ZIF-8 cavity dimensions (1.1 $\mathrm{nm}$ cages accessible through $0.34 \mathrm{~nm}$ windows) and, therefore, should be presumably located on the external surface of the material. 


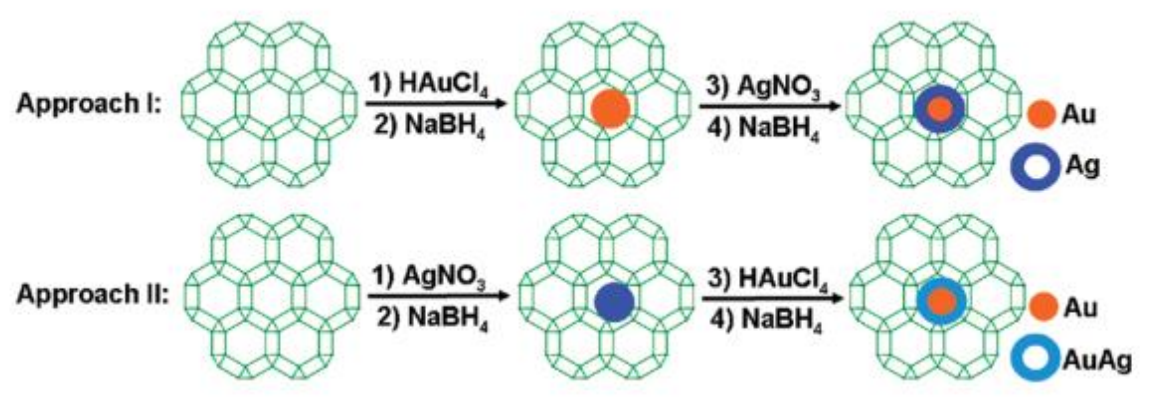

Figure 12. Two different approaches used for the preparation of Au@Ag core-shell NPs. Taken with permission from ref. ${ }^{82}$

Similarly, a bimetallic core-shell Au@Ag catalyst immobilized on MIL-101-SO $\mathrm{S}_{3} \mathrm{H}$ was formed by in-situ reduction of mixtures of $\mathrm{Au}$ and $\mathrm{Ag}$ precursors (Figure 13) and its catalytic activity studied for the reduction of 4-nitrophenol.83 Au@Ag NPs were formed well dispersed in the MOF crystals with small sizes in the range of 2-10 $\mathrm{nm}$. The reduction of 4-nitrophenol was complete in $12 \mathrm{~min}$ in the presence of $\mathrm{Au} @ \mathrm{Ag} / \mathrm{MIL}-101-\mathrm{SO}_{3} \mathrm{H}$, while the same reaction required 27 min with $\mathrm{Ag} / \mathrm{MIL}-101-\mathrm{SO}_{3} \mathrm{H}$, in accordance with an enhanced catalytic activity arising from the synergistic effect derived from the combination of $\mathrm{Au}$ and $\mathrm{Ag}$ metals with a core-shell nanostructure. It is important to disclose what can be the positive role of $\mathrm{SO}_{3} \mathrm{H}$ groups at the linker. Typically, $\mathrm{SO}_{3} \mathrm{H}$ groups are strongly acidic and as sufonate anions have interaction with metal cations, stabilizing their positive charges. XPS analysis could serve to address if there is an interaction of this sulfonate groups with Au@Ag NPs favouring the stabilization of partial positive charges on the surface of these NPs. Furthermore, it was noticed that an increase in the Ag content significantly improves the catalytic activity under the optimized conditions. This indicates that $\mathrm{Ag}$ content related to an increase in shell thickness can lead to an improvement of the catalytic activity, although the presence of the Au core is needed as deduced from the observation of the synergistic effect. The catalyst was 
stable up to five successive catalytic cycles, without showing significant decrease in its activity. Time conversion plots should have been provided to support the absence of catalyst deactivation under the experimental conditions.
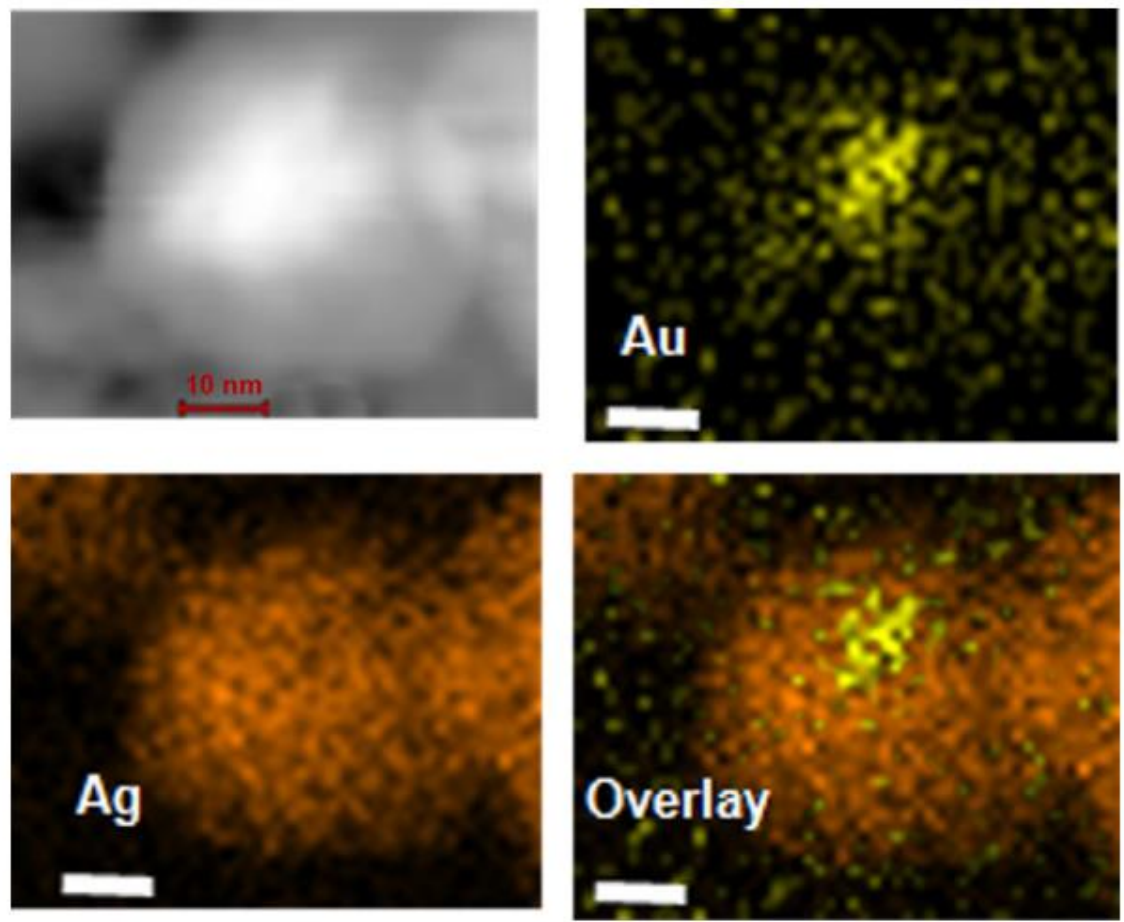

Figure 13. HAADF-STEM-EDX mapping of Au@Ag/MIL-101-SO ${ }_{3} \mathrm{H}$. Scale bar is $10 \mathrm{~nm}$. Taken with permission from ref. ${ }^{83}$

Recently, boron imidazolate frameworks (BIFs) have been reported to exhibit high porosity, showing catalytic and mechanochromic properties. ${ }^{123-126}$ BIF-38 has a three dimensional two-fold interpenetrating structure with open channels. In the structure of BIF38, each $\mathrm{Cu}^{+}$center is coordinated by three $\mathrm{N}$ atoms from three $\mathrm{BH}(\mathrm{im})_{3}$ ligands, exhibiting a planar trigonal coordination geometry. The tripodal $\mathrm{BH}(\mathrm{im})_{3}$ ligands link the triple coordinated $\mathrm{Cu}^{+}$centers resulting in a 3D framework (Figure 14). The potentially active $\mathrm{B}-\mathrm{H}$ bonds present in tridentate boron imidazolate ligands could serve as a reducing agent promoting the formation of MNPs inside the crystals without the need of any external reducing agent. As a 
realization of this idea, Au-Ag bimetallic NPs have been prepared within the crystal structure of BIF-38, affording AuAg@BIF-38. ${ }^{84}$ TEM image of AuAg@BIF-38 revealed the formation of ca. $20 \mathrm{~nm}$ AuAg bimetallic NPs, too large to be incorporated inside the MOF crystals. XPS of AuAg@BIF-38 showed the binding energies corresponding to metallic Ag and Au with no obvious peak for $\mathrm{Ag}^{+}$or $\mathrm{Au}^{3+}$. The powder XRD patterns confirmed the existence of BIF-38 framework after the loading of Au-Ag bimetallic NPs. The catalytic activity of AuAg@BIF-38 was evaluated in the reduction of 4-nitrophenol, observing the completion of the reaction within 6 min. ${ }^{84}$ The catalyst stability was ascertained by TEM measurements which indicate that the sizes of the Au-Ag NPs remain unaltered after three runs. However, no data were given regarding the initial reaction rates.
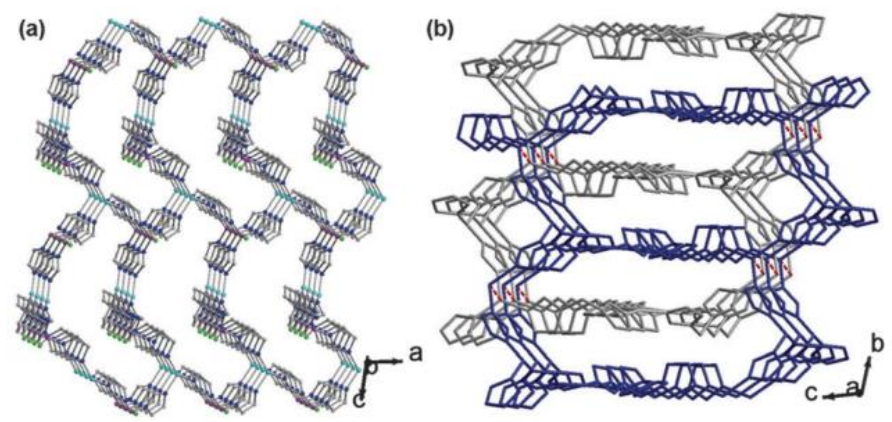

Figure 14. (a) View of an independent 3D framework of BIF-38; (b) view of the 2-fold interpenetrated structure of BIF-38, showing the $\mathrm{Cu}-\mathrm{Cu}$ interactions (red dashed line) between the frameworks. Taken with permission from ref. ${ }^{84}$

\section{Tandem reactions}

An area of much current interest in catalysis is process intensification by coupling two or more individual reactions in a single transformation. These so-called "tandem reactions" make accessible a product that requires two or more consecutive steps from the starting material. In most of the tandem reactions, the point is to achieve high selectivity towards a 
single product and, for this reason, most of the tandem reactions combine oxidation or reduction steps with others that require a totally different type of active sites such as acid or base catalysis. For tandem reactions, MOFs are particularly suited materials since they can have two or more different active sites located at different parts of the structure. The topic of MOFs as catalysts to promote tandem reactions has been reviewed in the literature. ${ }^{4,63}$ For instance, the encapsulated Au NPs can have oxidation/reduction activity, while the organic linker or the metal node can have the second type of active site. In one of these examples, alcohols are selectively oxidized to carbonyl compounds that then, subsequently, undergo aldolic condensation promoted by acid or basic sites. One of these examples of tandem reaction is the oxidation of benzyl alcohols coupled with Knoevenagel condensation.

Besides the reduction of 4-nitrophenol previously commented, Au@Cu(II)-MOF has also been tested for the aerobic oxidation of benzyl alcohol, reaching $95 \%$ conversion with $99 \%$ selectivity of benzaldehyde at $110{ }^{\circ} \mathrm{C} .{ }^{78}$ The powder XRD patterns showed also for this reaction the structural integrity of the lattice after five catalytic cycles. Furthermore, HRTEM image showed only a slight aggregation of Au NPs, but without influence on the activity of the catalyst in five consecutive cycles. These results encouraged the authors to use this catalyst for tandem reactions involving oxidation of benzyl alcohol to benzaldehyde followed by Knoevenagel condensation of the later product with malononitrile (Scheme 7). The TON and TOF for this tandem reaction are 32.67 and $1.48 \mathrm{~h}^{-1} .{ }^{78} \mathrm{HRTEM}$ analysis revealed that the mean diameter of the Au NPs slightly increases $(<5 \mathrm{~nm})$ after three runs, which was attributed to the occurrence of a slight aggregation of Au NPs during the cascade reaction. Thus, it seems that also in this case, the stability of $\mathrm{Au@Cu(II)} \mathrm{MOF} \mathrm{is} \mathrm{not} \mathrm{complete.}$ 


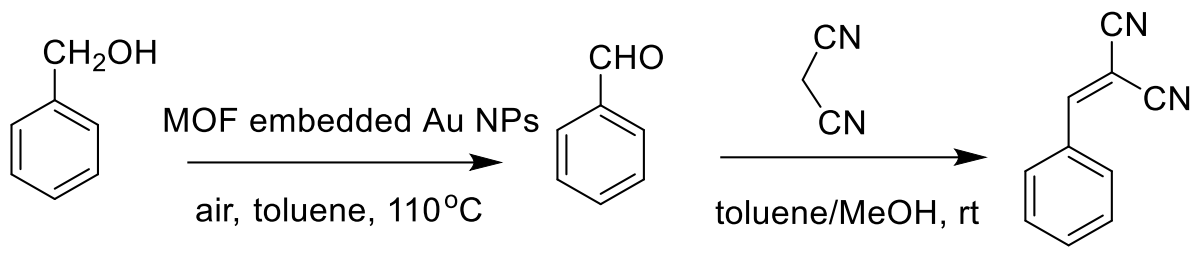

Scheme 7. Au@Cu(II)-MOFs promoted one-pot synthesis of 2-benzylidenemalononitrile.

Highly dispersed $\mathrm{Au}$ NPs were supported on $\mathrm{NH}_{2}-\mathrm{MIL}-53(\mathrm{Al})$ and its activity was examined in the cascade reaction involving aerobic oxidation of benzyl alcohols followed by Knoevenagel condensation (Scheme 7). ${ }^{85}$ It was confirmed that deposition of Au NPs has no impact on the crystal structure of $\mathrm{NH}_{2}-\mathrm{MIL}-53$. ICP-AES analysis indicated $1.2 \mathrm{wt} . \%$ of $\mathrm{Au}$ in Au@NH $2-M I L-53(A l) . T E M$ images showed uniform nanorods of $\mathrm{NH}_{2}-\mathrm{MIL}-53(\mathrm{Al})$ with a width of $35 \mathrm{~nm}$ and length of $210 \mathrm{~nm}$ (Figure 15). Also, HRTEM indicated monodispersed Au NPs evenly distributed on Au@-NH2-MIL-53(Al) with a mean diameter of $2.5 \mathrm{~nm}$ that is larger than the diagonal of the square channels of MIL-53(Al) structure (about $1.5 \mathrm{~nm}$ ). As it is indicated in the Scheme 7, adsorbed Au NPs catalyze aerobic oxidation of benzyl alcohol, while Knoevenagel condensation of benzaldehyde is believed to be promoted by amino groups. Au@NH $2-M I L-53(A l)$ constitutes a genuine example illustrating the opportunities that MOF offers to contain two or more different active sites cooperating to the success of the tandem reaction. A $99 \%$ yield of the benzylidenemalononitrile was obtained with 1 mol\% of Au@ $\mathrm{NH}_{2-}$ MIL-53(Al). In contrast, a physical mixture of Au NPs and $\mathrm{NH}_{2}-\mathrm{MIL}-53(\mathrm{Al})$ as catalyst resulted only in $16 \%$ yield. Furthermore, Au NPs with a size of $50 \mathrm{~nm}$ as catalyst gave $14 \%$ yield of benzaldehyde. In addition, Au NPs in combination with a homogeneous organic base were not able to achieve a satisfactory yield of the desired product. Only $4 \%$ of benzaldehyde and $14 \%$ of benylidenemalononitrile were obtained using Au NPs as the catalyst with aniline as base. It is believed that aniline has similar basicity as the organic linker in $\mathrm{NH}_{2}-\mathrm{MIL}-53(\mathrm{Al})$. These series of experiments clearly suggest that, as already commented in section 2 , the size 
and dispersion of Au NPs is crucial for the catalytic reactivity in the aerobic benzyl alcohol oxidation/Knoevenagel condensation reaction sequence. The yield of 2benzylidenemalononitrile (97 \%) was retained after five cycles. Furthermore, ICP-AES analysis showed the absence of Au leaching and the powder XRD pattern showed no changes in crystallinity for the five times recycled catalyst. However, time-conversion plots upon reuse were not provided.

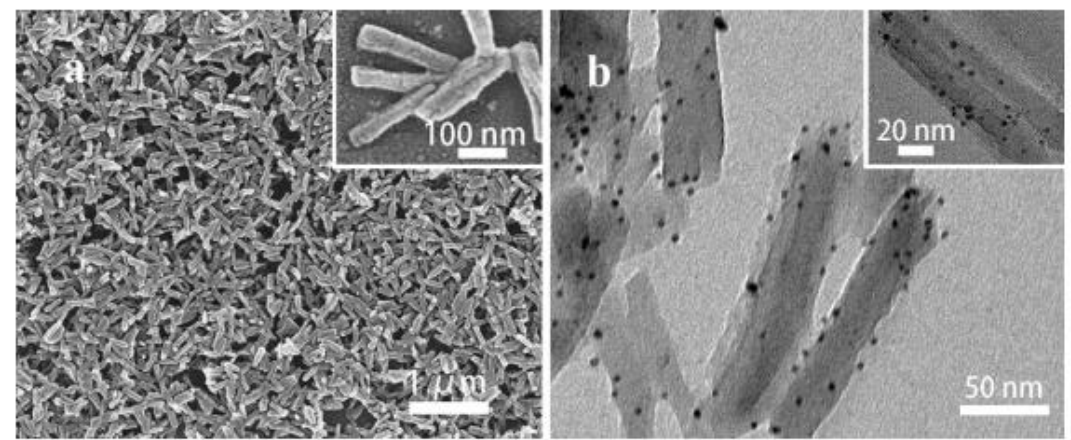

Figure 15. (a) SEM image of $\mathrm{NH}_{2}-\mathrm{MIL}-53(\mathrm{Al})$ and (b) HRTEM image of Au@NH $-\mathrm{MIL}-53(\mathrm{Al})$. Insets in (a) and (b) show their respective magnified images. Taken with permission from ref. ${ }^{85}$ Au NPs have been prepared with particle size smaller than $5 \mathrm{~nm}$ on MIL-53(Al), MOF5 and CPL-2 $\left[\mathrm{Cu}_{2}(\mathrm{pzdc})_{2}(\mathrm{bpy})\right]_{\mathrm{n}}$ (pzdc: pyrazine-2,3-dicarboxylate). ${ }^{86}$ Particularly, $80 \%$ of $\mathrm{Au}$ particles could be deposited as clusters with diameters below $1.6 \pm 1 \mathrm{~nm}$ over MIL-53(AI) that would be in accordance with the channel size of this material. The particle size of Au on MOF5 and CPL-2 is $3.3 \pm 2.3$ and $2.4 \pm 1.0$ respectively, larger than the pore sizes of these MOFs. The activity of these catalysts was examined in the one-pot synthesis of dibenzylamine from benzylamine by sequential oxidation/hydrogenation via the formation as intermediate of $\mathrm{N}$ benzylidenebenzylamine as shown in Scheme 8. Although, Au/CPL-2 and Au/MOF-5 resulted in high conversion towards the oxidation of benzylamine to $\mathrm{N}$-benzylidenebenzylamine, only a trace amount of dibenzylamine was observed. This result is not totally unexpected considering that while Au NPs show high activity for benzylamine aerobic oxidation, the 
hydrogenation activity of Au NPs is much lower. ${ }^{127}$ In contrast, Au/MIL-53(Al) exhibited the highest conversion in the oxidation step and also in the hydrogenation of $\mathrm{N}$ benzylidenebenzylamine intermediate to give $91 \%$ yield of the target dibenzylamine. This clearly indicates the higher activity of Au deposited on MIL-53(Al) that was attributed to its smaller particle size and uniform distribution. Bus and coworkers have found from hydrogen chemisorption measurements that hydrogen molecules were dissociated and adsorbed on the corners and the edges of Au particles and these locations increase in density as the particle size decreases. ${ }^{128}$ Accordingly, the higher catalytic activity of Au/MIL-53(Al) in hydrogenation could be mainly due to an increase in the fraction of Au atoms on the corners and the edges derived from a decrease in the size of $A u$, although a positive role of the MIL53(Al) support in this reaction cannot be excluded.

A comparative study of $\mathrm{Au} / \mathrm{MIL}-53(\mathrm{Al})$ with $\mathrm{Au} / \mathrm{TiO}_{2}$ (average Au particle size $2.9 \pm 0.5$ $\mathrm{nm}$ ) as catalyst shows that dibenzylamine was not formed as product and resulted in only $43 \%$ yield of $\mathrm{N}$-benzylidenebenzylamine. These catalytic data can be understood considering the role that particle size and support plays in Au catalysis and shows clearly the beneficial advantage that MOFs as porous matrices can have over other supports, due to the stabilization of remarkably small Au NPs with high dispersion.

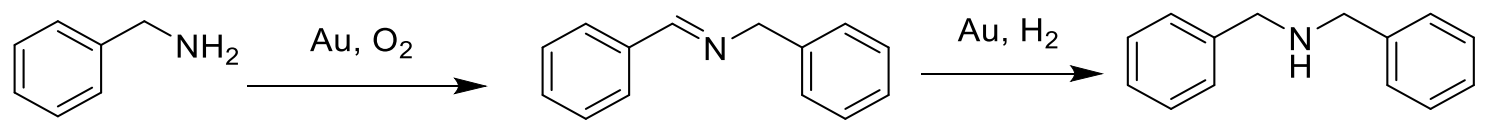

Scheme 8. One-pot synthesis of dibenzylamine through a sequence of oxidation followed by hydrogenation.

The high activity of Au@NH $2-U i O-66$ in base-free aerobic oxidation of benzyl alcohol and reduction of 4-nitrophenol led to anticipate that this material should also be efficient to promote a sequence of reactions involving aerobic oxidation and transfer hydrogenation. In 
this way, it has been possible to perform amine $\mathrm{N}$-alkylation by employing benzyl alcohol as alkylating agent and aniline as the starting amine, the product being secondary amines (Scheme 9). ${ }^{71}$ This tandem sequence involves an aerobic oxidation of benzyl alcohol to benzaldehyde, condensation of the later product to give the corresponding imine and the final hydrogenation to obtain the secondary amine (Scheme 9). Optimization of the various reaction conditions resulted in 53\% yield of $\mathrm{N}$-benzylaniline using $\mathrm{Au} @ \mathrm{NH}_{2}-\mathrm{UiO}-66$ as catalyst via one-pot tandem reactions. This is one of the few examples for the synthesis of $\mathrm{N}$ benzylaniline through a one-pot approach ${ }^{86,129,130}$ and, certainly $\mathrm{Au} @ \mathrm{NH}_{2}-\mathrm{UiO}-66$ is among the catalysts giving the highest N-benzylamine yields. In contrast, unsupported Au NPs, Au@TiO 2 and Au@PANI only reached low N-benzylamine yield under the optimal reaction conditions (Table 4). Au@PANI gave the highest conversion of benzyl alcohol, but led to only 19\% yield of $\mathrm{N}$-benzylaniline. On the other hand, Au@ $\mathrm{NH}_{2}-\mathrm{UiO}-66$ exhibits a much higher yield of $\mathrm{N}$-benzylaniline and does not require the addition of an inorganic base. Au@ $\mathrm{NH}_{2}-\mathrm{UiO}-66$ maintained its activity for the formation of $\mathrm{N}$-benzylaniline with no loss of reactivity after five runs, but further confirmation of the lack of catalytic deactivation is needed.

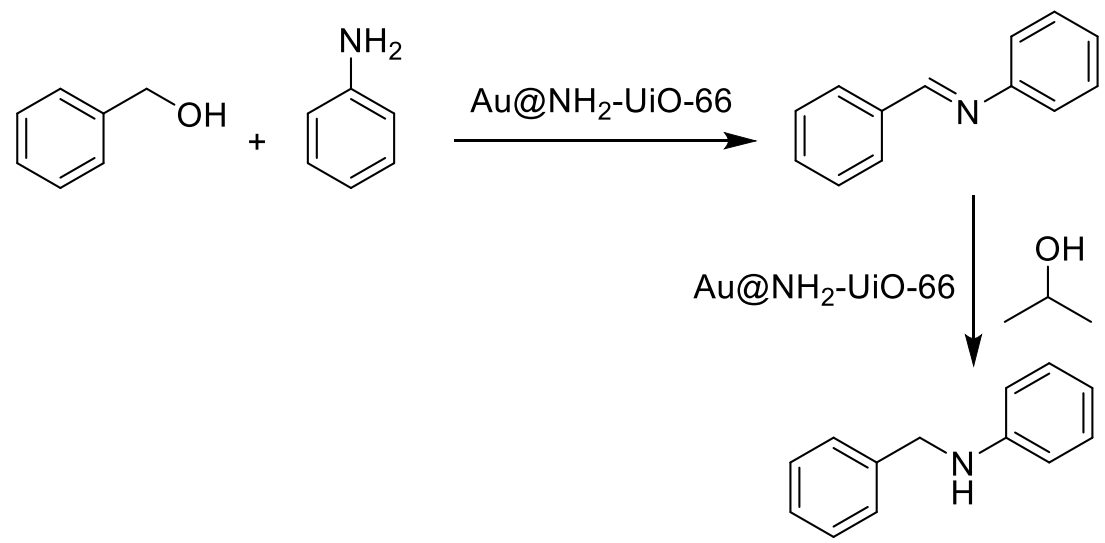

Scheme 9. N-alkylation of aniline using benzyl alcohol in the presence of Au@NH - UiO-66. 
Table 4. Aniline N-alkylation with benzyl alcohol via oxidation/imine formation/transfer hydrogenation reactions. ${ }^{a}$ Data taken from ref. ${ }^{71}$

\begin{tabular}{|c|c|c|c|c|c|}
\hline Entry & Catalyst/Conditions & $\mathrm{T}\left({ }^{\circ} \mathrm{C}\right)$ & $\begin{array}{l}\text { Benzyl } \\
\text { alcohol } \\
\text { con. (\%) }\end{array}$ & $\begin{array}{l}\text { Yield of } \\
\text { Imine (\%) }\end{array}$ & $\begin{array}{l}\text { Yield of } \mathrm{N} \text { - } \\
\text { benzylaniline } \\
\text { (\%) }\end{array}$ \\
\hline 1 & No catalyst/DMF & 100 & - & - & - \\
\hline 2 & Au@NH2-UiO-66/DMF & 100 & 18 & 11 & 5 \\
\hline 3 & Au@NH ${ }_{2}-U i O-66 /$ toluene & 100 & 39 & 13 & 21 \\
\hline $4^{b}$ & Au@NH${ }_{2}-U i O-66 /$ toluene & 100 & 99 & 77 & 14 \\
\hline 5 & Au@NH${ }_{2}$-UiO-66/xylene & 130 & 76 & 13 & 53 \\
\hline 6 & Unsupported Au/xylene & 130 & 14 & $<5$ & 10 \\
\hline 7 & Au@TiO 2 /xylene & 130 & 23 & 11 & 10 \\
\hline 8 & Au@PANI/xylene & 130 & 38 & 14 & 19 \\
\hline
\end{tabular}

aReaction conditions: aniline (1 mmol), benzyl alcohol (1 mmol), 2 mol\% Au@ @ $\mathrm{NH}_{2}$-UiO-66 (1.8 $w t \%)$ and solvent ( $2 \mathrm{~mL}$ ) were stirred under $\mathrm{N}_{2}$ atmosphere for $12 \mathrm{~h}$, then 2-propanol (6 mmol)

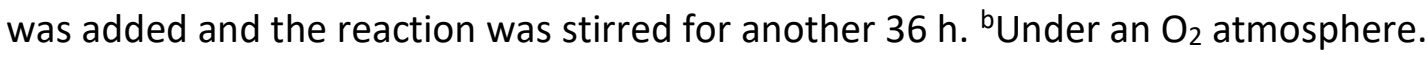

Besides 4-nitrophenol reduction, Au@MOF-3 was examined for one-pot reduction of nitrobenzene followed by coupling of aniline to azobenzene in the presence of 2-3 equivalents of $\mathrm{NaBH}_{4}$ (Scheme 10). ${ }^{79}$ Reduction of 4-nitrophenol in the presence of Au@MOF-3 in EtOH yielded the corresponding azo compound, while the same reaction in aqueous medium yielded 4-aminophenol. A control experiment with only $\mathrm{NaBH}_{4}$ did not produce either the corresponding amine or azo compound. On the other hand, detailed mechanistic investigations through time dependent ${ }^{1} \mathrm{H}-\mathrm{NMR}$ spectroscopy indicated that Au@MOF-3 catalyzed reduction in water is extremely fast, which resulted in the formation of the 
completely reduced product (amine) in high selectivity, however, in ethanol the reduction process is slow enough to produce the coupling product $(a z o)^{79}$ between aniline and the nitrosobenzene intermediate, due to the coexistence of significant concentrations of both compounds (Scheme 10).

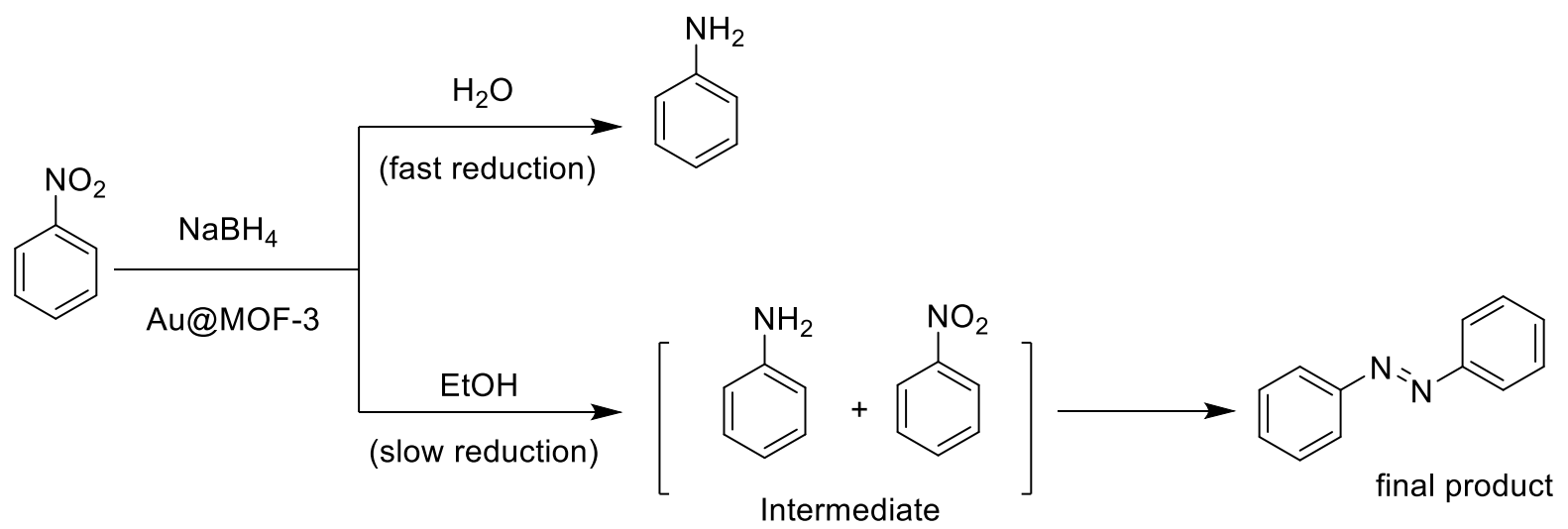

Scheme 10.Au@MOF-3 catalyzed conversion of nitrobenzene to azobenzene through aniline.

Activation of a terminal alkyne $\mathrm{C}-\mathrm{H}$ bond by transition metal catalysts is a reaction of fundamental interest in organic synthesis ${ }^{131,132}$ since it forms new C-C bonds. One of the best examples of such process is the three components coupling between aldehydes, alkynes, and amines, namely, $A^{3}$ coupling. The resulting propargylamines or $\beta$-amino alkynes are important versatile synthetic intermediates for the preparation of polyfunctional amino derivatives and as biologically active compounds. ${ }^{133,134}$

Au functionalized IRMOF-3 (pore size $0.96 \mathrm{~nm}$ ) was synthesized in two different methods, either by post covalent modification or by one-pot synthesis. ${ }^{87}$ Post synthetic covalent modification resulted in $4.6 \%$ of $\mathrm{Au}$ with a significant fraction of cationic $\mathrm{Au}$ $\left(\mathrm{Au}^{3+} / \mathrm{Au}^{0}=0.2\right)$, while one-pot synthesis afforded materials with either $3.2 \mathrm{wt} . \%$ or $0.6 \mathrm{wt} . \%$ of Au. Powder XRD patterns of the Au functionalized IRMOF-3 by post covalent modification exhibited some changes in the crystal lattice compared to that of the parent IRMOF-3, indicating some deformation, shrinkage or even the collapse of pores during the modification 
process. ${ }^{87}$ In contrast, the samples obtained by one-pot synthesis at 0.6 or $3.2 \mathrm{wt} . \%$ loading exhibited a crystallinity comparable to that of the pristine IRMOF-3. Au NPs were present as spheres with average diameters of $3.3,1.7$, and $2.5 \mathrm{~nm}$ for $4.6 \% \mathrm{Au} / \mathrm{IRMOF}-3$ (post-synthetic modification), 0.6\%Au/IRMOF-3 and 3.2\%Au/IRMOF-3, respectively. The activity of these Au catalysts was tested in $\mathrm{A}^{3}$ coupling of benzaldehyde, phenylacetylene and piperidine leading to propargylamines in dioxane at $120{ }^{\circ} \mathrm{C}$ (Scheme 11). It was observed that the $4.6 \%$ Au/IRMOF-3 catalyst prepared by post covalent modification exhibited higher catalytic activity at $120{ }^{\circ} \mathrm{C}$ than that of $3.2 \%$ or $0.6 \%$ Au/IRMOF-3 prepared by one-pot method, although the former exhibits much lower crystallinity than the latter two catalysts. This enhanced activity of the less-crystalline catalyst was attributed to the existence of a fraction of cationic Au atoms. Considering the total Au content, the specific reaction rates at the maximum conversions were calculated to be $120.5,9.2$, and $3.6 \mathrm{mmol} \mathrm{g}_{\mathrm{Au}}{ }^{-1} \mathrm{~h}^{-1}$ for $4.6 \%$ Au/IRMOF-3, 0.6\% Au/IRMOF-3, and 3.2\% Au/IRMOF-3, respectively, showing that the reaction rate of $4.6 \% \mathrm{Au} / \mathrm{IRMOF}-3$ is one order of magnitude higher than those of $0.6 \% \mathrm{Au} /$ IRMOF-3 and 3.2\%Au/IRMOF-3. Reusability tests showed that the activity of 4.6\%Au/IRMOF-3 decreases from a benzaldehyde conversion of 77 to $66 \%$ indicating the occurrence of gradual deactivation of catalyst. This activity decay upon reuse is correlated to the agglomeration of Au NPs, whose average size increases to $13.8 \mathrm{~nm}$, with maximum sizes up to $34.5 \mathrm{~nm}$. Although the location of these larger NPs are not discussed, based on their size, they should be located on the external surface of the crystallites after the reaction. Furthermore, deactivation of $4.6 \% \mathrm{Au} /$ IRMOF-3 could also be partly due to the reduction of $\mathrm{Au}^{3+}$, as shown in the thermoprogrammed reduction analysis with hydrogen, and to the detectable Au leaching (ca. 5\%) over the recycled 4.6\%Au/IRMOF-3. As expected in view of their higher intrinsic reactivity, aliphatic aldehydes such as cyclohexanecarboxaldehyde and 
n-octanal exhibited higher activities than aromatic aldehydes with the 4.6\%Au/IRMOF-3, 0.6\%Au/IRMOF-3, and 3.2\%Au/IRMOF-3. Thus, although adsorption of Au NPs on IRMOF has resulted in an active catalyst for $A^{3}$ coupling, there is still room for improvement, developing a crystalline MOF containing Au NPs that do not grow in size under the reaction conditions. It should be noted that the use of secondary amines as reagents with high basicity and chelating ability represents a challenge for MOF stability and it would be advisable to check separately the MOF stability in the presence of these reagents and products under reaction conditions.<smiles>O=Cc1ccccc1</smiles><smiles>c1ccncc1</smiles>

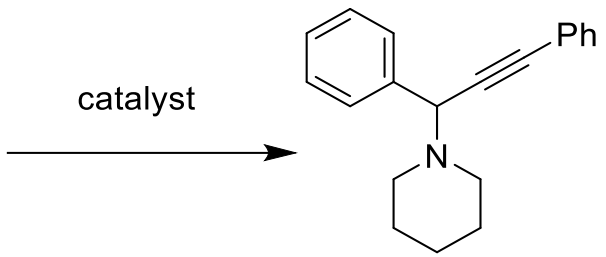

Scheme 11. Synthesis of propargylamine from benzaldehyde, piperidine and phenylacetylene.

A homochiral Zn-containing MOF, namely CUP-1 (CUP: China University of Petroleum), was prepared by using mixture of ABDC (ABDC: 2-amino-1,4-benzenedicarboxylic acid) and Llactic acids (L-lac) as linkers in a one-pot synthesis resulting in a solid with the formula of $\mathrm{Zn}_{2}(\mathrm{ABDC})(\mathrm{L}-\mathrm{lac})(\mathrm{HCOO}) .{ }^{88}$ Chiral CUP-1 was modified by incorporating Au NPs either in onepot or post-synthetic strategies, introducing catalytic activity by interaction with the free amino groups present. Au-functionalized CUP-1 prepared by the post-synthetic method contains a mixture of $\mathrm{Au}^{0}$ and $\mathrm{Au}^{3+}$, while the catalyst prepared with the one-step method shows ultrafine metallic Au NPs with an average size of $2.1 \mathrm{~nm}$. Au/CUP-1(PSM) exhibited 89 $\%$ yield in the $\mathrm{A}^{3}$ coupling between benzaldehyde, piperidine and phenylacetylene to the corresponding propargylamine at $120^{\circ} \mathrm{C}$ after $4 \mathrm{~h}$ (TON 14). In contrast, Au/CUP-1(OP) showed a $79 \%$ yield of propargylamine (TON 556) at longer times and higher temperatures. The reusability of the Au/CUP-1(PSM) and Au/CUP-1(OP) catalysts was checked for the coupling of benzaldehyde, piperidine and phenylacetylene at 120 and $150{ }^{\circ} \mathrm{C}$, respectively. It 
was noticed that Au/CUP-1(PSM) undergoes a significant deactivation by around $33 \%$ in the first run, but further recycling leads to slower deactivation suggesting that there are two different deactivation mechanisms. Au/CUP-1(OP) also undergoes some deactivation from the first to the second use conversions changing from 75,82 to $72 \%$ for three successive runs after 5,13 , and $13 \mathrm{~h}$, respectively. It seems, however, that chirality of the CUP-1 host does not play any role in the process and is not fully justified in the present case.

\section{Photoredox Reactions}

It has been frequently found in photocatalysis that the activity of a semiconductor can be significantly enhanced by the presence of MNPs as co-catalysts facilitating the oxidation or reduction of substrates on the surface of the materials. ${ }^{65} \mathrm{Au}$ is one of the favourite cocatalysts for photocatalytic reduction reactions, with the additional advantage of exhibiting a surface plasmon in the visible region that can serve to introduce photoresponse in this range of wavelengths (Scheme 12). ${ }^{135,136}$ Considering that MOFs are being now widely used as photocatalysts, ${ }^{65,137,138}$ it is not surprising that some of the MOF containing Au NPs have been also screened on photocatalysis.

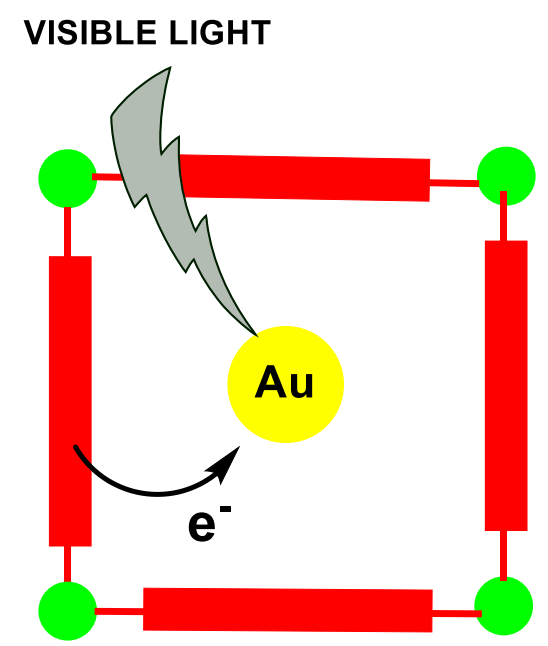


Scheme 12. Possible roles of incorporated Au NPs as co-catalyst in reduction by acting as electron reservoirs, as co-catalysts and as visible light harvesters due to the presence of a plasmon band $\left(\lambda_{\max }=560 \mathrm{~nm}\right)$.

Metal NPs doped over $\mathrm{NH}_{2}-\mathrm{MIL}-125$ (Ti) (Pt or $\mathrm{Au}$ ) were prepared and their effect on the photocatalytic performance of $\mathrm{NH}_{2}-\mathrm{MIL}-125(\mathrm{Ti})$ has been examined in saturated $\mathrm{CO}_{2}$ using triethanolamine (TEOA) as sacrificial agent under visible-light irradiation. ${ }^{89}$ The size of the Pt clusters was about $3 \mathrm{~nm}$ in Pt/NH $2-\mathrm{MIL}-125(\mathrm{Ti})$, while the size of Au NPs was $2.5 \mathrm{~nm}$ in Au/NH $2^{-}$ MIL-125(Ti). The production rate of $\mathrm{HCOO}^{-}$with $\mathrm{NH}_{2}-\mathrm{MIL}-125$ (Ti) was $10.75 \mu \mathrm{mol}$ after $8 \mathrm{~h}$. In comparison, $\mathrm{Au} / \mathrm{NH}_{2}-\mathrm{MIL}-125(\mathrm{Ti})$ exhibited under similar conditions $9.06 \mu \mathrm{mol}$ of $\mathrm{HCOO}^{-}$at 8 h, which is lower by $16 \%$ compared to pure $\mathrm{NH}_{2}-\mathrm{MIL}-125$ (Ti). On the other hand, $\mathrm{Pt} / \mathrm{NH}_{2}-\mathrm{MIL}-$ 125 (Ti) showed an enhancement in the production of $\mathrm{HCOO}^{-}$after $8 \mathrm{~h}$ to the value of 12.96 $\mu \mathrm{mol}$, which is about $21 \%$ increase in the activity as compared to pristine $\mathrm{NH}_{2}-\mathrm{MIL}-125(\mathrm{Ti})$. It was noticed that the amount of $\mathrm{HCOO}^{-}$increases almost linearly with the irradiation time over both metal containing $\mathrm{NH}_{2}-\mathrm{MIL}-125(\mathrm{Ti})$. This indicates that both metal-containing $\mathrm{NH}_{2}-\mathrm{MIL}-$ $125(\mathrm{Ti})$ are stable during the photocatalytic reactions and the lower amount of $\mathrm{HCOO}^{-}$ observed with $\mathrm{Au} / \mathrm{NH}_{2}-\mathrm{MIL}-125(\mathrm{Ti})$ is not due to photocatalyst deactivation during the irradiation time. This influence of the presence of metal co-catalyst is, however, very minor in absolute terms with respect to the activity of possible $\mathrm{NH}_{2}-\mathrm{MIL}-125(\mathrm{Ti})$ and surely does not justify the use of costly noble metals.

In addition of direct light absorption by MOFs, these materials can be hosts of light harvesters components. Incorporation of a light harvester inside the MOF pores has the advantage that makes available a large series of compounds and MNPs that are widely used in photocatalysis in other systems, integrating photo-sensitizers and catalytic sites into a single material. ${ }^{139}$ One of these cases are MNPs of some transition metals, like $\mathrm{Au}$, that exhibit visible light absorption due to the plasmon 
resonance band. The plasmon absorption band corresponds to the collective excitation of electrons confined in a space of nanometric dimensions and in the case of Au NPs appears at about $560 \mathrm{~nm}$. Upon excitation of Au plasmon band with visible light, electrons from Au NP are ejected and can populate conduction bands of semiconductors or can be trapped at the nodal positions in MOFs. ${ }^{140}$ In this way, the Au@MOF becomes photoresponsive under visible light irradiation that is one of the major problems encountered in solar photocatalysis.

In this context, $\mathrm{NH}_{2}-\mathrm{UiO}-66$ was used as host materials to load Au NPs to investigate the plasmon-enhanced photocatalytic performance of MOFs. ${ }^{90}$ It was expected that the small spectral overlap between the absorption edge of $\mathrm{NH}_{2}-\mathrm{UiO}-66(450 \mathrm{~nm})$ and the plasmon band of $\mathrm{Au}$ NPs $\left(450-700 \mathrm{~nm}, \lambda_{\max } \sim 560 \mathrm{~nm}\right.$ ) should effectively extend the range of light absorption..$^{90}$ On the other hand, other of the main objectives of this study was to develop a small molecule-assisted nucleation-growth route to facilitate the formation of Zr-oxo clusters on Au NPs to achieve Au@NH$-U$-UiO-66 core-shell structures. It was believed that this core Au@shell ( $\mathrm{NH}_{2}$-UiO-66) should provide the optimal morphology for observation of this

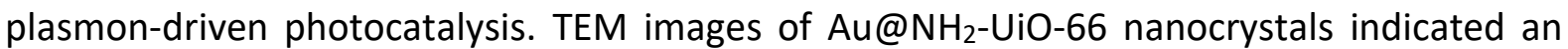
average diameter of $240 \mathrm{~nm}$ for the few Au NP-free $\mathrm{NH}_{2}-\mathrm{UiO}-66$ nanocrystals (Figure 16). The morphology of most $\mathrm{NH}_{2}-\mathrm{UiO}-66$ shells was deviated from the common UiO-66 octahedral shapes presenting multifaceted crystals, while large Au NPs were incorporated into the matrices. Powder XRD revealed that $\mathrm{NH}_{2}-\mathrm{UiO}-66$ in the heterostructures possesses high crystallinity with preferential growth in the 110 direction (Figure 16) with the characteristic diffraction peaks of the 111 crystal plane of Au NPs. For Au@NH 2 -UiO-66 composites prepared in the presence of acetic acid or $\mathrm{CO}_{2}$, the content of Au NPs was about $2.3 \%$ and $2.4 \%$, respectively, as evidenced by ICP-AES. The photocatalytic activity of $\mathrm{NH}_{2}$-UiO-66 enhanced by the plasmon resonance band of Au NPs was evaluated for the photocatalytic 
oxidation of alcohol using a white fluorescence lamp for $24 \mathrm{~h}$ under oxygen atmosphere. The conversion of benzyl alcohol with very high selectivity of benzaldehyde $>99 \%$ appeared to be $26.2 \%$ and $30.0 \%$ using $\mathrm{Au} @ \mathrm{NH}_{2}-\mathrm{UiO}-66$ in acetic acid or $\mathrm{CO}_{2}$ as a catalyst, while $4.5 \%$ conversion was achieved with $\mathrm{NH}_{2}-\mathrm{UiO}-66$ as photocatalyst. ${ }^{90} \mathrm{~A}$ lower photocatalytic activity was observed with other $\mathrm{NH}_{2}-\mathrm{UiO}-66$ having different amounts of $\mathrm{Au}$ NPs compared to aforementioned 2.3\% Au loading $\mathrm{Au} @ \mathrm{NH}_{2}-\mathrm{UiO}-66$. It was, however, observed that the photocatalytic performance was strongly dependent on the structure of substrates. For example, Au@ $\mathrm{NH}_{2}-\mathrm{UiO}-66$ in acetic acid or $\mathrm{CO}_{2}$ and $\mathrm{NH}_{2}-\mathrm{UiO}-66$ showed similarly low photocatalytic activities (<3\%) using 2,4,6-trimethylbenzyl alcohol as a substrate. This was due to the relatively large size of the substrate $(6.1 \AA)$ that cannot diffuse through the pores to approach Au cores and the photo oxidation was only catalyzed by activated sites located at the external surface of MOFs. 

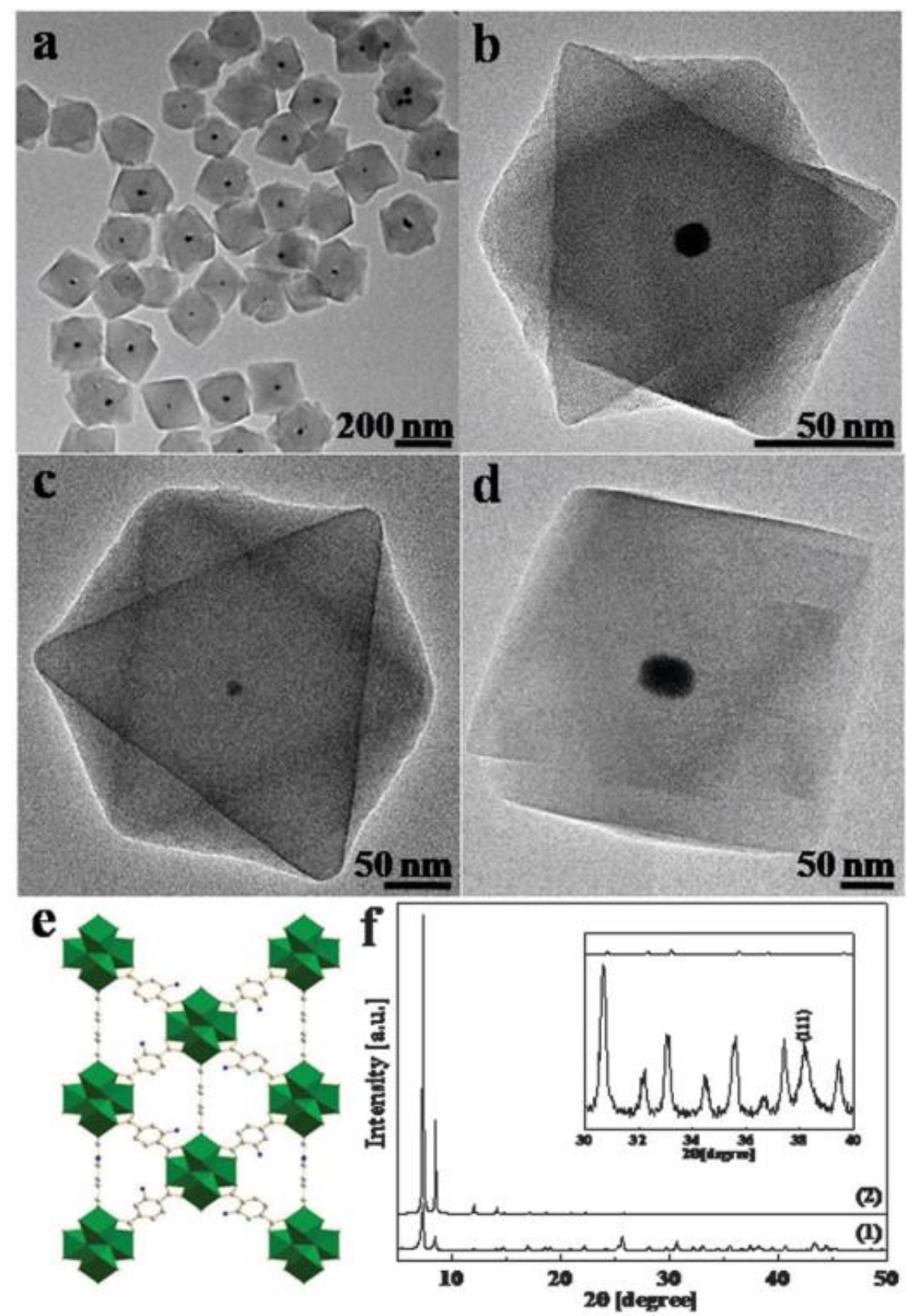

Figure 16. As-synthesized Au@ $\mathrm{NH}_{2}-\mathrm{UiO}-66$ (a) panoramic and (b-d) magnified TEM images with different Au cores in size; (e) schematic illustration of crystal structures of $\mathrm{NH}_{2}-\mathrm{UiO}-66$ along the 110 direction; (f) XRD patterns of (1) Au@NH 2 -UiO-66 and (2) simulated UiO-66. (Inset is the magnified XRD patterns from $30^{\circ}$ to $40^{\circ}$ ). Taken with permission from ref. ${ }^{90}$

\section{Summary and Future Prospects}


As commented in the introduction, the purpose of this mini review has been to show the excellent catalytic performance of Au NPs when incorporated inside MOFs that exhibit structural robustness. From the current state of the art, it seems that this high catalytic activity derives from the combination of three main factors, i.e., i) the small particle size that can be achieved following certain preparation procedures, ii) high dispersion and homogeneous distribution of NPs throughout the crystal, and iii) the structural stability of MOF lattice that stabilizes the hosted NPs against growth and agglomeration.

Even though the number of research articles in this area is large, there is still, in our opinion, room for further developments expanding the reactions in which these MOFs embedded Au NPs can be used as catalysts showing the synergy that can be gained in certain cases from the combination of MOFs and Au NPs. With respect to new reactions, the potential of Au@MOFs in tandem process is evident considering that the catalytic activity of Au NPs can be complemented by the activity of the metal nodes or organic linkers constituting the MOF network. At the moment, the examples of these tandem reactions is still limited and rely almost exclusively and the combination of amino groups on the linker with the oxidation activity of Au NPs.

With regard to aerobic oxidations, two major issues still require further clarification to have a more clear understanding of the role and potential of Au@MOFs, i.e., determination of the reaction mechanism and more specifically whether or not the role of Au@MOFs is just as initiators of radical chains or as catalysts in where each product molecule is formed in contact with the active sites. The second issue refers to the improved selectivity for aerobic oxidations when using Au@MOFs. It is particularly important to establish the importance of hydrophilicity/hydrophobicity of the internal pores on the control of the product distribution 
and if by tuning hydrophilicty, it is possible to further increase the selectivity towards the target keto/ol mixture with respect to the results obtained in homogeneous phase.

A final aspect that needs further development in the future is the incorporation of $\mathrm{Au}$ alloys, either with core shell structure or random distribution and what are the gain in activity and selectivity that can be obtained. At the moment, the number of examples is quite limited and refers to the modulation of the $\mathrm{Ag}$ activity for $\mathrm{NaBH}_{4}$ activation by $\mathrm{Au}$ and $\mathrm{Au}-\mathrm{Pd}$ alloys in alicyclic or benzylic oxidations. This field of metal alloys is also particularly promising in the applications of metal incorporated MOFs in photocatalysis. In this case, it can be imagined that MOFs can contain two different cocatalysts specifically designed to manage photogenerated electrons and holes for the target reductions and oxidations, respectively.

Finally, although, for the sake of brevity, we have limited to the case of Au because for this metal the particle size is a strong limiting parameter, it is clear that the conclusions reached in this review can very likely be extended to other noble or semi noble metals and even metal oxides. This means that also for some other metals highly performing materials are obtained by encapsulating MNPs inside MOFs with robust structure.

\section{Acknowledgements}

ADM thanks University Grants Commission (UGC), New Delhi for the award of Assistant Professorship under its Faculty Recharge Programme. ADM also thanks Department of Science and Technology, India, for the financial support through Fast Track project (SB/FT/CS-166/2013) and the Generalidad Valenciana for financial aid supporting his stay at Valencia through the Prometeo programme. Financial support by the Spanish Ministry of Economy and Competitiveness (CTQ-2015-69153-CO2-R1 and Severo Ochoa) and Generalidad Valenciana (Prometeo 2013-014) is gratefully acknowledged. 


\section{References}

(1) Farrusseng, D.; Aguado, S.; Pinel, C. Angew. Chem., Int. Ed. 2009, 48, 7502.

(2) Qiu, S.; Zhu, G. Coord. Chem. Rev. 20092532891.

(3) Liu, J.; Chen, L.; Cui, H.; Zhang, J.; Zhang, L.; Su, C.-Y. Chem. Soc. Rev. 2014, 43, 6011.

(4) Gascon, J.; Corma, A.; Kapteijn, F.; Llabrés i Xamena, F. X. ACS Catal. 2014, 4, 361.

(5) Chughtai, A. H.; Ahmad, N.; Younus, H. A.; Laypkov, A.; Verpoort, F. Chem. Soc. Rev. 2015, 44, 6804.

(6) Dhakshinamoorthy, A.; Asiri, A. M.; Garcia, H. Chem. Soc. Rev. 2015, 44, 1922.

(7) Corma, A.; Garcia, H.; Llabrés i Xamena, F. X. Chem. Rev. 2010, 1104606.

(8) Du, D.-Y.; Qin, J.-S.; Li, S.-L.; Su, Z.-M.; Lan, Y.-Q. Chem. Soc. Rev. 2014, 43, 4615.

(9) Gu, Z.-Y.; Park, J.; Raiff, A.; Wei, Z.; Zhou, H.-C. ChemCatChem 2014, 6, 67.

(10) Natarajan, S.; Mahata, P. Chem. Soc. Rev. 2009, 38, 2304.

(11) Almeida Paz, F. A.; Klinowski, J.; Vilela, S. M. F.; Tome, J. P. C.; Cavaleiro, J. A. S.; Rocha, J. Chem. Soc. Rev. 2012, 41, 1088.

(12) Foo, M. L.; Matsuda, R.; Kitagawa, S. Chem. Mater. 2014, 26, 310.

(13) Chen, T.-H.; Popov, I.; Kaveevivitchai, W.; Miljanić, O. S. Chem. Mater. 2014, 26, 4322.

(14) Lu, W.; Wei, Z.; Gu, Z.-Y.; Liu, T.-F.; Park, J.; Park, J.; Tian, J.; Zhang, M.; Zhang, Q.; Gentle III, T.et al. Chem. Soc. Rev. 2014, 43, 5561.

(15) Lin, Z.-J.; Lü, J.; Hong, M.; Cao, R. Chem. Soc. Rev. 2014, 43, 5867.

(16) Farha, O. K.; Eryazici, I.; Jeong, N. C.; Hauser, B. G.; Wilmer, C. E.; Sarjeant, A. A.; Snurr, R. Q.; Nguyen, S. T.; Özgür Yazaydın, A.; Hupp, J. T. J. Am. Chem. Soc. 2012, 134, 15016.

(17) Xuan, W.; Zhu, C.; Liu, Y.; Cui, Y. Chem. Soc. Rev. 2012, 41, 1677.

(18) Dhakshinamoorthy, A.; Garcia, H. Chem Soc Rev. 2012, 41, 5262.

(19) Rösler, C.; Fischer, R. A. CrystEngComm 2015, 17, 199.

(20) Moon, H. R.; Lim, D.-W.; Suh, M. P. Chem. Soc. Rev. 2013, 42, 1807.

(21) Falcaro, P.; Ricco, R.; Yazdi, A.; Imaz, I.; Furukawa, S.; Maspoch, D.; Ameloot, R.; Evans, J. D.; Doonan, C. J. Coord. Chem. Rev. 2016, 307, 237-254.

(22) Takale, B. S.; Bao, M.; Yamamoto, Y. Org. Biomol. Chem. 2014, 12, 2005.

(23) Grunwaldt, J.-D.; Maciejewski, M.; Becker, O. S.; Fabrizioli, P.; Baiker, A. J. Catal. 1999, 186, 458.

(24) Primo, A.; Corma, A.; García, H. Phys. Chem. Chem. Phys 2011, 13, 886.

(25) Carrettin, S.; Concepción, P.; Corma, A.; López Nieto, J. M.; Puntes, V. F. Angew. Chem., Int. Ed. 2004, 43, 2538.

(26) Casanova, O.; Iborra, S.; Corma, A. ChemSusChem 2009, 2, 1138.

(27) Primo, A.; Marino, T.; Corma, A.; Molinari, R.; García, H. J. Am. Chem. Soc. 2011, 1336930.

(28) Wu, P.; Bai, P.; Yan, Z.; Zhao, G. X. S. Sci. Rep. 2016, 6, 18817.

(29) Jia, J.; Haraki, K.; Kondo, J. N.; Domen, K.; Tamaru, K. J. Phys. Chem. B 2000, 104, 11153.

(30) Grisel, R. J. H.; Kooyman, P. J.; Nieuwenhuys, B. E. J. Catal. 2000, 191, 430.

(31) Haruta, M.; Tsubota, S.; Kobayashi, T.; Kageyama, H.; Genet, M. J.; Delmon, B. J. Catal. 1993, 144, 175.

(32) Ishida, T.; Koga, H.; Okumura, M.; Haruta, M. Chem. Rec. 2016, 16, 2278.

(33) Haruta, M.; Daté, M. Appl. Catal. A: Gen. 2001, 222427.

(34) Min, B. K.; Friend, C. M. Chem. Rev. 2007, 107, 2709.

(35) Stratakis, M.; Garcia, H. Chem. Rev. 2012, 112, 4469.

(36) Hvolbaek, B.; Janssens, T. V. W.; Clausen, B. S.; Falsig, H.; Christensen, C. H.; Nørskov, J. K. NanoToday 2007, 2, 14.

(37) Valden, M.; Lai, X.; Goodman, D. W. Science 1998, 281, 1647. 
(38) van Bokhoven, J. A.; Louis, C.; Miller, J. T.; Tromp, M.; Safonova, O. V.; Glatzel, P. Angew. Chem. Int. Ed. 2006 45, 4651.

(39) Hammer, B. Top. Catal. 2006, 37, 3.

(40) Carrettin, S.; McMorn, P.; Johnston, P.; Griffin, K.; Kiely, C. J.; Attard, G. A.; Hutchings, G. J. Top. Catal. 2004, 27, 131.

(41) Imperor-Clerc, M.; Bazin, D.; Appay, M.-D.; Beaunier, P.; Davidson, A. Chem. Mater. 2004, 16, 1813.

(42) Aijaz, A.; Karkamkar, A.; Choi, Y. J.; Tsumori, N.; Rönnebro, E.; Autrey, T.; Shioyama, H.; Xu, Q. J. Am. Chem. Soc. 2012, 134, 13926-13929.

(43) Zhu, Q.-L.; Li, J.; Xu, Q. J. Am. Chem. Soc. 2013, 135, 10210-10213.

(44) Wang, D.; Li, Z. J. Catal. 2016, 342151.

(45) Sun, D.; Li, Z. J. Phys. Chem. C 2016, 120, 19744-19750.

(46) Aijaz, A.; Xu, Q. J. Phys. Chem. Lett. 2014, 5, 1400-1411.

(47) Meilikhov, M.; Yusenko, K.; Esken, D.; Turner, S.; Van Tendeloo, G.; Fischer, R. A. Eur. J. Inorg. Chem. 2010, 3701-3714.

(48) Esken, D.; Turner, S.; Lebedev, O. I.; Tendeloo, G. V.; Fischer, R. A. Chem. Mater. 2010, 22, 6393.

(49) Hermes, S.; Schröter, M.-K.; Schmid, R.; Khodeir, L.; Muhler, M.; Tissler, A.; Fischer, R. W.; Fischer, R. A. Angew. Chem., Int. Ed. 2005, 44, 6237-6241.

(50) Ishida, T.; Nagaoka, M.; Akita, T.; Haruta, M. Chem.-Eur. J. 2008, 14, 8456.

(51) Jiang, H.-L.; Lin, Q.-P.; Akita, T.; Liu, B.; Ohashi, H.; Oji, H.; Honma, T.; Takei, T.; Haruta, M.; Xu, Q. Chem. -Eur. J. 2011, 17, 78-81.

(52) Liu, X.-H.; Ma, J.-G.; Niu, Z.; Yang, G.-M.; Cheng, P. Angew. Chem., Int. Ed. 2015, 54, 988-991.

(53) Tsuruoka, T.; Kawasaki, H.; Nawafune, H.; Akamatsu, K. ACS Appl. Mater. Interfaces 2011, 3, 3788.

(54) Lu, G.; Li, S.; Guo, Z.; Farha, O. K.; Hauser, B. G.; Qi, X.; Wang, Y.; Wang, X.; Han, S.; Liu, X.et al. Nat. Chem. 2012, 4, 310-316.

(55) Gole, B.; Sanyal, U.; Banerjee, R.; Mukherjee, P. S. Inorg. Chem. 2016, 55, 2345-2354.

(56) Hartley, F. R. Chem. Rev. 1969, 69, 799-844.

(57) Zhang, K.; Cutler, J. I.; Zhang, J.; Zheng, D.; Auyeung, E.; Mirkin, C. A. J. Am. Chem. Soc. 2010, 132, 15151-15153.

(58) Dhakshinamoorthy, A.; Asiri, A. M.; Garcia, H. Chem. Commun. 2014, 50, 12800.

(59) Wang, C.; Liu, X.; Keser Demir, N.; Chen, J. P.; Li, K. Chem. Soc. Rev. 2016, 45, 5107.

(60) Dhakshinamoorthy, A.; Alvaro, M.; Garcia, H. Chem. Commun. 2010, 46, 6476.

(61) Dhakshinamoorthy, A.; Alvaro, M.; Concepción, P.; García, H. Catal. Commun. 2011, 12, 1018.

(62) Serna, P.; Corma, A. ACS Catal. 2015, 5, 7114.

(63) Dhakshinamoorthy, A.; Garcia, H. ChemSusChem 2014 7,2392.

(64) Huang, Y.-B.; Liang, J.; Wang, X.-S.; Cao, R. Chem. Soc. Rev. 2017, 46, 126.

(65) Dhakshinamoorthy, A.; Asiri, A. M.; Garcia, H. Angew. Chem., Int. Ed. 2016 55, 5414.

(66) Muller, M.; Turner, S.; Lebedev, O. I.; Wang, Y.; Tendeloo, G. V.; Fischer, R. A. Eur. J. Inorg. Chem. 2011, 1876.

(67) Liu, H.; Liu, Y.; Li, Y.; Tang, Z.; Jiang, H. J. Phys. Chem. C 2010, 114, 13362.

(68) Juan-Alcañiz, J.; Ferrando-Soria, J.; Luz, I.; Serra-Crespo, P.; Skupien, E.; Santos, V. P.; Pardo, E.; Llabrés i Xamena, F. X.; Kapteijn, F.; Gascon, J. J. Catal. 2013, 307, 295.

(69) Zhu, J.; Wang, P. C.; Lu, M. Appl. Catal. A: Gen. 2014, 477, 125.

(70) Leus, K.; Concepcion, P.; Vandichel, M.; Meledina, M.; Grirrane, A.; Esquivel, D.; Turner, S.; Poelman, D.; Waroquier, M.; Van Speybroeck, V.et al. RSC Adv. 2015, 5, 22334.

(71) Luan, Y.; Qi, Y.; Gao, H.; Zheng, N.; Wang, G. J. Mater. Chem. A 2014, 2, 20588.

(72) Sun, Z.; Li, G.; Liu, L.; Liu, H.-O. Catal. Commun. 2012, 27, 200.

(73) Long, J.; Liu, H.; Wu, S.; Liao, S.; Li, Y. ACS Catal. 2013, 3, 647-654.

(74) Liu, H.; Chen, G.; Jiang, H.; Li, Y.; Luque, R. ChemSusChem 2012, 5, 1892. 
(75) Liu, H.; Li, Y.; Jiang, H.; Vargas, C.; Luque, R. Chem. Commun. 2012, 48, 8431.

(76) Wu, R.; Qian, X.; Zhou, K.; Liu, H.; Yadian, B.; Wei, J.; Zhu, H.; Huang, Y. J. Mater. Chem. A 2013, $1,14294$.

(77) Ke, F.; Zhu, J.; Qiu, L.-G.; Jiang, X. Chem. Commun., 2013, 49, 1267.

(78) Wang, J.-S.; Jin, F.-Z.; Ma, H.-C.; Li, X.-B.; Liu, M.-Y.; Kan, J.-L.; Chen, G.-J.; Dong, Y.-B. Inorg. Chem. 2016, 55, 6685-6691.

(79) Gole, B.; Sanyal, U.; Mukherjee, P. S. Chem. Commun. 2015, 51, 4872.

(80) Ke, F.; Wang, L.; Zhu, J. Nanoscale 2015, 7, 1201.

(81) Bao, C.; Zhou, L.; Shao, Y.; Wu, Q.; Zhu, H.; Li, K. J. Ind. Eng. Chem. 2016, 38132.

(82) Jiang, H.-L.; Akita, T.; Ishida, T.; Haruta, M.; Xu, Q. J. Am. Chem. Soc. 2011, 133, 1304.

(83) Huang, P.; Ma, W.; Yu, P.; Mao, L. Chem. Asian J. 2016, 11, 2705.

(84) Wen, T.; Zhang, D.-X.; Liu, J.; Zhang, H.-X.; Zhang, J. Chem. Commun. 2015, 51, 1353.

(85) Wang, X. B.; Qin, Y. L.; Zhu, L. H.; Tang, H. Q. Nitrogen-Doped Reduced Graphene Oxide as a Bifunctional Material for Removing Bisphenols: Synergistic Effect between Adsorption and Catalysis. Environmental Science \& Technology 2015, 49 (11), 6855.

(86) Ishida, T.; Kawakita, N.; Akita, T.; Haruta, M. Gold Bull. 2009, 42, 267.

(87) Lili, L.; Xin, Z.; Jinsen, G.; Chunming, X. Green Chem. 2012, 14, 1710.

(88) Lili, L.; Xin, Z.; Shumin, R.; Ying, Y.; Xiaoping, D.; Jinsen, G.; Chunming, X.; Jing, H. RSC Adv. 2014, 4, 13093.

(89) Sun, D.; Liu, W.; Fu, Y.; Fang, Z.; Sun, F.; Fu, X.; Zhang, Y.; Li, Z. Chem. Eur. J. 2014, 20, 4780.

(90) Gu, Z.; Chen, L.; Duan, B.; Luo, Q.; Liu, J.; Duan, C. Chem. Commun. 2016, 52, 116.

(91) Sheldon, R. A.; van Bekkum, H. Fine Chemicals Through Heterogeneous Catalysis John Wiley \& Sons Inc. The Netherlands 2001, 1.

(92) Mandal, S.; Santra, C.; Bando, K. K.; James, O. O.; Maity, S.; Mehta, D.; Chowdhury, B. J. Mol. Catal. A: Chem. 2013, 378, 47.

(93) Wang, H.; Fan, W.; He, Y.; Wang, J.; Kondo, J. N.; Tatsumi, T. J. Catal. 2013, 29910.

(94) Zheng, N. F.; Stucky, G. D. Chem. Commun. 2007, 3862.

(95) Kandiah, M.; Ussegqlio, S.; Svelle, S.; Olsbye, U.; Lillerud, K. P.; Tilset, M. J. Mater. Chem. 2010, 20, 9848.

(96) Guo, H. F.; Al-Hunaiti, A.; Kemell, M.; Rautiainen, S.; Leskela, M.; Repo, T. ChemCatChem 2011, 3, 1872.

(97) Costa, V. V.; Estrada, M.; Demidova, Y.; Prosvirin, I.; Kriventsov, V.; Cotta, R. F.; Fuentes, S.; Simakov, A.; Gusevskaya, E. V. J. Catal. 2012, 292, 148.

(98) Santiago-Portillo, A.; Navalón, S.; Cirujano, F. G.; Llabrés i Xamena, F. X.; Alvaro, M.; Garcia, H. ACS Catal. 2015, 5, 3216.

(99) Wu, P.; Bai, P.; Lei, Z.; Loh, K. P.; Zhao, X. S. Microporous MesoporousMater. 2011, 141, 222.

(100) Chowdhury, B.; Bravo-Suarez, J. J.; Mimura, N.; Lu, J.; Bando, K. K.; Tsubota, S.; Haruta, M. J. Phys. Chem. B 2006, 110, 22995.

(101) Stiehl, J. D.; Kim, T. S.; McClure, S. M.; Mullins, C. B. J. Am. Chem. Soc. 2004, 126, 1606.

(102) Hereijgers, B. P. C.; Weckhuysen, B. M. J. Catal. 2010, 270, 16.

(103) Yu, H.; Peng, F.; Tan, J.; Hu, X.; Wang, H.; Yang, J.; Zheng, W. Angew. Chem., Int. Ed. 2011, 50, 3978.

(104) Larsen, R. G.; Saladino, A. C.; Hunt, T. A.; Mann, J. E.; Xu, M.; Grassian, V. H.; Larsen, S. C. J. Catal. 2001, 204, 440.

(105) Sun, H.; Blatter, F.; Frei, H. J. Am. Chem. Soc. 1996, 118, 6873.

(106) Faust, T. B.; D'Alessandro, D. M. RSC Adv. 2014, 4, 17498.

(107) Mikami, Y.; Dhakshinamoorthy, A.; Alvaro, M.; Garcia, H. ChemCatChem 2013 5,1964.

(108) Dhakshinamoorthy, A.; Alvaro, M.; Garcia, H. Chem. Eur. J. 2011, 17, 6256.

(109) Kesavan, L.; Tiruvalam, R.; Rahim, M. H. A.; bin Saiman, M. I.; Enache, D. I.; Jenkins, R. L.; Dimitratos, N.; Lopez-Sanchez, J. A.; Taylor, S. H.; Knight, D. W.et al. Science 2011, 331, 195.

(110) Jiang, H. L.; Liu, B.; Akita, T.; Haruta, M.; Sakurai, H.; Xu, Q. J. Am. Chem. Soc. 2009, 131, 11302. 
(111) Toal, S. J.; Trogler, W. C. J. Mater. Chem. 2006, 16, 2871.

(112) Zhang, Z.; Shao, C.; Zou, P.; Zhang, P.; Zhang, M.; Mu, J.; Guo, Z.; Li, X.; Wang, C.; Liu, Y. Chem. Commun. 2011, 47, 3906.

(113) Gangula, A.; Podila, R.; Ramakrishna, M.; Karanam, L.; Janardhana, C.; Rao, A. M. Langmuir 2011, 27, 15268.

(114) Hermannsdorfer, J.; Friedrich, M.; Miyajima, N.; Albuquerque, R. Q.; Kummel, S.; Kempe, R. Angew. Chem., Int. Ed. 2012, 51, 11473.

(115) Chen, G. J.; Wang, J. S.; Jin, F. Z.; Liu, M. Y.; Zhao, C. W.; Li, Y. A.; Dong, Y. B. Inorg. Chem. 2016, 55, 3058-3064.

(116) Grirrane, A.; García, H.; Corma, A.; Álvarez, E. Chem. Eur. J. 2013, 19, 12239.

(117) Leyva-Pérez, A.; Oliver-Meseguer, J.; Cabrero-Antonino, J. R.; Rubio-Marqués, P.; Serna, P.; AlResayes, S. I.; Corma, A. ACS Catal. 2013, 3, 1865.

(118) Maity, P.; Takano, S.; Yamazoe, S.; Wakabayashi, T.; Tsukuda, T. J. Am. Chem. Soc. 2013, 135 9450.

(119) Wen, X.; Li, G.; Chen, Q.; Zhang, H.; Ba, X.; Bai, G. Ind. Eng. Chem. Res. 2014, 5311646.

(120) Zeng, T.; Zhang, X.; Guo, Y.; Niu, H.; Cai, Y. J. Mater. Chem. A 2014, 2, 14807.

(121) Li, J.; Liu, C.-Y.; Liu, Y. J. Mater. Chem. A 2012, 228426.

(122) Kuroda, K.; Ishida, T.; Haruta, M. J. Mol. Catal. A: Chem. 2009, 2987.

(123) Zhang, H. X.; Fu, H. R.; Li, H. Y.; Zhang, J.; Bu, X. Chem. Eur. J. 2013, 19, 11527.

(124) Wang, F.; Shu, Y. B.; Zhang, J.; Bu, X. Chem. - Eur. J. 2012, 18, 11876.

(125) Zhang, H. X.; Wang, F.; Yang, H.; Tan, Y. X.; Zhang, J.; Bu, X. J. Am. Chem. Soc. 2011, 133, 11884.

(126) Zhang, J.; Wu, T.; Zhou, C.; Chen, S.; Feng, P.; Bu, X. Angew. Chem., Int. Ed. 2009, 48, 2542.

(127) Serna, P.; Boronat, M.; Corma, A. Top. Catal. 2011, 54, 439.

(128) Bus, E.; Miller, J. T.; Van Bokhoven, J. A. J. Phys. Chem. B 2005, 109, 14581.

(129) Liu, H.; Chuah, G. K.; Jaenicke, S. J. Catal. 2012, 292, 130.

(130) Demir, S.; Coskun, F.; Ozdemir, I. J. Organomet. Chem. 2014, 755, 134.

(131) Li, C. J. Acc. Chem. Res. 2002, 35, 533.

(132) Park, S. B.; Alper, H. Chem. Commun. 2005, 1315.

(133) Huffman, M. A.; Yasuda, N.; DeCamp, A. E.; Grabowski, E. J. J. J. Org. Chem. 1995, 60, 1590.

(134) Konishi, M.; Ohkuma, H.; Tsuno, T.; Oki, T.; VanDuyne, G. D.; Clardy, J. J. Am. Chem. Soc. 1990, $112,3715$.

(135) Kochuveedu, S. T.; Kim, D.-P.; Kim, D. H. J. Phys. Chem. C 2012, 1162500.

(136) Sarina, S.; Waclawik, E. R.; Zhu, H. Green Chem. 2013, 15, 1814.

(137) Wang, S.; Wang, X. Small 2015 11, 3097.

(138) Meyer, K.; Ranocchiari, M.; Van Bokhoven, J. A. Energy Environ. Sci. 2015, 8, 1923.

(139) Zhang, T.; Lin, W. Chem. Soc. Rev. 2014, 43, 5982.

(140) Nasalevich, M. A.; van der Veen, M.; Kapteijn, F.; Gascon, J. CrystEngComm 2014, 16, 4919. 